\title{
Respiratory medicines for children: current evidence, unlicensed use and research priorities
}

\author{
A.R. Smyth, A. Barbato, N. Beydon, H. Bisgaard, K. de Boeck, P. Brand, A. Bush, \\ B. Fauroux, J. de Jongste, M. Korppi, C. O'Callaghan, M. Pijnenburg, F. Ratjen, \\ K. Southern, D. Spencer, A. Thomson, H. Vyas, A. Warris and P.J. Merkus
}

ABSTRACT: This European Respiratory Society task force has reviewed the evidence for paediatric medicines in respiratory disease occurring in adults and children. We describe offlicence use, research priorities and ongoing studies.

Off-licence and off-label prescribing in children is widespread and potentially harmful. Research areas in asthma include novel formulations and regimens, and individualised prescribing. In cystic fibrosis, future studies will focus on screened infants and robust outcome measures are needed. Other areas include new enzyme and antibiotic formulations and the basic defect. Research into pneumonia should include evaluation of new antibacterials and regimens, rapid diagnostic tests and, in pleural infection, antibiotic penetration, fibrinolytics and surveillance. In uncommon conditions, such as primary ciliary dyskinesia, congenital pulmonary abnormalities or neuromuscular disorders, drugs indicated for other conditions (e.g. dornase alfa) are commonly used and trials are needed. In neuromuscular disorders, the $\beta$-agonists may enhance muscle strength and are in need of evaluation. Studies of antibiotic prophylaxis, immunoglobulin and antifungal drugs are needed in immune deficiency.

We hope that this summary of the evidence for respiratory medicines in children, highlighting gaps and research priorities, will be useful for the pharmaceutical industry, the paediatric committee of the European Medicines Agency, academic investigators and the lay public.

KEYWORDS: Clinical trails, evidence-based medicine, paediatric respiratory diseases, pharmacotherapy

\section{CONTENTS}

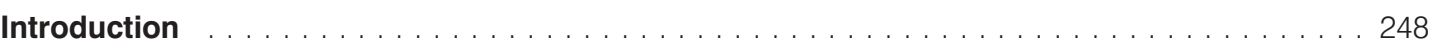



Inhaled and oral corticosteroids, old and new . . . . . . . . . . . . . . . . . . . . . . . . . . . 248

Leukotriene receptor antagonists . . . . . . . . . . . . . . . . . . . . . . . . . . . . . . . . . 249

Short- and long-acting bronchodilators for acute and chronic asthma . . . . . . . . . . . . . 250

Other anti-inflammatory and immunosuppressive agents . . . . . . . . . . . . . . . . . . . . 250

Acute severe asthma . . . . . . . . . . . . . . . . . . . . . . . . . . . . 251

Cystic fibrosis . . . . . . . . . . . . . . . . . . . . . . . . . . . . . . . . 251

Therapies for use in children identified by newborn screening . . . . . . . . . . . . . . . . . . 251

Gastrointestinal interventions for CF . . . . . . . . . . . . . . . . . . . . . . . . . . . 252

Rational use of antibiotics . . . . . . . . . . . . . . . . . . . . . . . . . . . . . . 253

Fungal infection and allergic bronchopulmonary aspergillosis . . . . . . . . . . . . . . . . . . . . 254

Mucolytics and drugs that restore airway surface liquid . . . . . . . . . . . . . . . . . . . . . . 254

Novel antibacterials . . . . . . . . . . . . . . . . . . . . . . . . . . . . . . . . 255

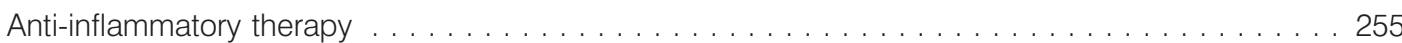

AFFILIATIONS

For affiliations details, please see the Acknowledgements section.

CORRESPONDENCE

A.R. Smyth

University of Nottingham Division of Child Health

Queens Medical Centre

Nottingham

NG7 2UH

UK

E-mail: alan.smyth@

nottingham.ac.uk

Received:

Sept 102008

Accepted after revision:

June 262009

First published online:

Nov 062009

European Respiratory Journal Print ISSN 0903-1936 Online ISSN 1399-3003 
Primary ciliary dyskinesia . . . . . . . . . . . . . . . . . . 256

Management of community-acquired pneumonia in children . . . . . . . . . . . . . . . . . . . . . 256

Pleural infection in children . . . . . . . . . . . . 257

Congenital abnormalities of the tracheobronchial tree

and lung parenchyma

258

Neuromuscular diseases, sleep disorders and thoracic

malformations in children

258

\section{INTRODUCTION}

Over half of children in Europe who are prescribed medicines in hospital receive a medication that is either "unlicensed" or "off label" [1]. "Unlicensed" use occurs when there is no manufacturing authorisation in children (and sometimes none in humans). This includes drugs that are modified to produce a suitable paediatric formulation. There may be some evidence of safety and efficacy for off-licence use, but not of the standard required for a marketing authorisation. "Off-label" use refers to the use of a licensed medication outside the terms of its manufacturing authorisation. For example, a drug may have a manufacturing authorisation but be used in a unapproved regimen (e.g. intermittent use of montelukast). Although there may be some evidence for this approach, this is not sufficient to grant a manufacturing authorisation. Another example of offlabel use is where a drug licensed in older children is used for younger children, where the pathology of the condition is different, e.g. dornase alfa in children aged under 5 yrs with cystic fibrosis (CF). These examples of prescribing off-label involve uses that do not have sufficient evidence for safety and efficacy and it arises because, until recently, there have been important obstacles to developing medicines for paediatric use.

In order to tackle the problem of paediatric drug development being delayed (or not taking place at all), there have recently been important changes in the regulatory environment for clinical studies of children's medicines [2]. The European Union (EU) paediatric regulation now requires every drug in development to have a paediatric investigation plan (with the incentive of 6 months' extra market exclusivity if this is followed). These plans are reviewed by the paediatric committee of the European Medicines Agency (EMEA). There are incentives to undertake clinical trials in off-patent medications where the evidence for their use in children is lacking. There has also been a move to set up a European clinical trials network in medicines for children, with national networks already established in some EU member states, such as the UK [3].

This report summarises the work of one of two European Respiratory Society (ERS) task force groups set up to review the evidence for the use of respiratory medicines in children, identify off-licence and off-label prescribing and suggest priorities for future clinical research. Where there is an established research programme undertaken by pharmaceutical or academic researchers (e.g. into drugs correcting the basic defect of $C F$ ), then we have not listed this as a priority. This is not because these areas are not important, but because clinical trials are already underway or planned. This report is confined to medicines used for eight major respiratory disorders, occurring in both adults and children (see Contents list). Medications used for conditions exclusive to
Pharmacotherapy for respiratory complications in children with neuromuscular diseases and thoracic malformations ... . 258

Pharmacotherapy for respiratory complications in children with sleep disorders

Pharmacotherapy for respiratory tract infections in children with immunological disorders

Conclusion 260

children are reported in a separate document [4]. A task force report on viral-induced wheeze in preschool children has been published [5].

The studies described in this task force report have been identified from a search of Medline, using appropriate MESH terms for each section, use of Cochrane systematic reviews, and studies known to the task force members. We have also listed studies which are ongoing, based on the direct knowledge of task force members and a search of publicly available clinical trials registers. Information regarding the marketing authorisation for drugs discussed in this review has been taken from the Summary of Product Characteristics (SPC). These are available in the Medicines Compendium [6]. However, licensing regulations may be subject to the laws of individual EU member states and readers are advised to consult their national regulations.

\section{ASTHMA}

\section{Inhaled and oral corticosteroids, old and new}

Evidence base

Since asthma was recognised as an inflammatory disease of the airways, inhaled corticosteroids (ICS) have become the mainstay of asthma therapy in children. In school-aged children and adolescents, ICS have been shown to improve symptoms, rescue medication use, lung function, airway hyperresponsiveness, quality of life and exacerbation rates [7, 8]. Most children with asthma on low-dose ICS treatment attain adequate control of their asthma and normal lung function [9]. Both the magnitude of the beneficial effect and the amount of variables that improve during treatment are superior to other treatment options [7, 10-12].

There are some differences between different ICS in their potency and their risk of side-effects. Regular dose (up to $400 \mu \mathrm{g}$ per day of budesonide equivalent) ICS therapy is safe, for both short- and long-term treatment. For example, although a mild attenuation of height growth has been observed during the first year of ICS therapy, this appears to be transient, and adult height seems to be normal $[13,14]$. Other systemic sideeffects, such as adrenal suppression, have only been documented with high-dose therapy [15]. "Difficult" asthma is defined as asthma which is not controlled, in spite of ICS doses of $>800 \mu \mathrm{g}$ per day of budesonide equivalent [16]. Novel formulations with small particles of ICS have comparable effects, though at a lower dose, than traditional formulations $[17,18]$. The potential for systemic absorption of small particle ICS should be the subject of further pharmacokinetic and safety evaluations.

In preschool children, ICS are effective as maintenance treatment for multiple-trigger wheeze [19], but less so in 
episodic viral wheeze. Maintenance treatment of multipletrigger wheeze in preschool children with ICS does not prevent its progression to asthma at school age [20,21]. This subject is discussed in detail elsewhere [5]. ICS are ineffective in preventing wheeze after respiratory syncytial virus (RSV) infection [22].

Oral corticosteroids are effective in the treatment of asthma exacerbations [23, 24]. Although high-dose ICS may be as effective as oral corticosteroids in acute severe asthma, the low cost of oral corticosteroids, and the low risk of side-effects of an isolated course make oral prednisolone the preferred treatment option [25]. Oral prednisolone solution is better tolerated than crushed tablets in young children, with equal efficacy [26]. Oral corticosteroids do not appear to be effective in wheezy infants below the age of $1 \mathrm{yr}[27,28]$ and a recent large randomised controlled trial has shown no effect in children with viral wheeze 1-5 yrs of age [29].

In the Global Initiative for Asthma (GINA) guidelines, montelukast is proposed to be an alternative treatment option to low-dose ICS for patients aged 2-15 yrs with mild persistent asthma, who do not have a recent history of serious attacks that required oral corticosteroid use, and who have demonstrated that they are not capable of using ICS [30]. However, randomised controlled trials comparing ICS and montelukast have given conflicting results [10,31]. Most children over 5 yrs of age can use steroid inhalers correctly.

\section{Current marketing authorisation}

ICS

The manufacturing authorisation depends on the drug, the product and the device. Beclomethasone, budesonide and fluticasone are each available as either a metered dose inhaler (MDI) or a dry powder inhaler (DPI). In general, DPIs are not licensed for use in preschool children and administration of DPIs requires an inhalation technique that most preschool children cannot be expected to perform. The maximum licensed daily dose in children is $400 \mu \mathrm{g}$ for beclomethasone and fluticasone and $800 \mu \mathrm{g}$ for budesonide. Fluticasone is nominally equivalent to beclomethasone or budesonide at half the dose. It is not licensed in children aged under 4 yrs. Mometasone and ciclesonide are not licensed for those aged under 12 yrs.

\section{Oral corticosteroids}

Authorisation is for any child who requires systemic corticosteroids for acute severe asthma. In certain European countries administration of betamethasone as soluble tablets is an alternative to administration as an oral solution of predinisolone.

\section{Current unlicensed and off-label use}

There is no off-label use in asthma; however, off-licence use for other conditions, such as chronic nonspecific cough, is common.

\section{Important research questions}

1) To what extent is poor control in children with asthma during ICS maintenance therapy due to intrinsically "difficult" asthma versus modifiable factors, such as poor adherence, poor inhalation technique or contributing factors (such as allergic rhinitis and dysfunctional breathing)? 2) What is the added value of fine particle, peripherally deposited corticosteroids compared with conventional ICS? 3) Can the response of individuals to ICS be predicted by phenotype or genotype?

\section{Ongoing studies}

At the time of writing, there are 22 trials of ICS for asthma in children currently enrolling, as listed on clinicaltrials.gov [32].

\section{Leukotriene receptor antagonists}

\section{Evidence base}

Montelukast is the only cysteinyl leukotriene receptor antagonist licensed for the treatment of asthma in schoolchildren and young children (down to 6 months of age) [33].

\section{Montelukast in multiple-trigger wheeze}

In one study, montelukast provided protection against bronchoconstriction induced by hyperventilation with cold, dry air [34] and, in a further randomised controlled trial, 4 weeks of montelukast improved airway hyperresponsiveness to methacholine by one doubling dose, compared with placebo [35]. The bronchoprotective effect was independent of concurrent steroid treatment. In a multicentre study of 689 young children (aged 2-5 yrs) with multiple-trigger wheeze, montelukast improved symptoms and achieved a 30\% reduction in exacerbations [33]. There are no studies in this age group comparing montelukast with ICS.

Montelukast in episodic (viral) wheeze

Daily use of montelukast over a 1-yr period reduced the rate of wheezing episodes in 549 children aged 2-5 yrs with episodic (viral) wheeze by $32 \%$ compared with placebo (number needed to treat 12) [36]. A trial of short-term treatment with montelukast as add-on to current treatment (90\% ICS) during the viral season in children aged 2-14 yrs reduced asthma worsening days by $53 \%$ and unscheduled physician visits by $78 \%$ (number needed to treat to prevent one exacerbation $<10$ ) [37]. A trial of intermittent montelukast, started when patients aged 2-14 yrs developed signs of a common cold, compared with placebo in 220 children with episodic wheeze showed a $30 \%$ reduction in unscheduled health visits (number needed to treat 11), but no effect on hospitalisations, duration of episode, and $\beta$-agonist and prednisolone use [38]. A large clinical trial in young children has shown that montelukast does not reduce symptoms, in most children, when given for a period of up to 24 weeks after RSV bronchiolitis [39].

\section{Current marketing authorisation}

Montelukast is indicated in the treatment of asthma as add-on therapy in those patients aged 2-15 yrs with mild to moderate persistent asthma who are inadequately controlled on ICS and in whom "as needed" short-acting $\beta$-agonists (SABAs) provide inadequate clinical control of asthma.

Montelukast may also be an alternative treatment option to low-dose ICS for patients aged 2-15 yrs with mild persistent asthma, who do not have a recent history of serious asthma attacks that required oral corticosteroid use, and who have demonstrated that they are not capable of using ICS.

Montelukast is also indicated in the prevention of asthma attacks in which the predominant component is exerciseinduced bronchoconstriction in children 2-15 yrs of age. 


\section{Current unlicensed and off-label use}

In those aged 2-15 yrs, as a first-line treatment in children with episodic asthma or mild to moderate persistent asthma. In those aged 0-2 yrs, for treatment of various forms of asthmarelated symptoms.

\section{Important research questions}

1) Who benefits from montelukast as add-on to ICS? 2) What is the effect of montelukast on symptoms of the common cold? 3) Is there any benefit from montelukast in post-bronchiolitis wheeze, where symptoms are severe?

\section{Ongoing and planned studies}

At the time of writing, there are 24 trials of montelukast in children on clinicaltrials.gov that are currently recruiting [40].

\section{Short- and long-acting bronchodilators for acute and chronic asthma}

\section{Evidence base}

As-needed SABAs are the first choice for rescue treatment of acute asthma in children. Regular, daily use of SABAs may cause deterioration of asthma and is not recommended. However, the scientific basis for this in children is limited [41]. The evidence for beneficial effects of SABAs in wheezing infants is lacking, due to lack of suitable end-points and the heterogeneity of wheezing in this age group. Regular SABA use does not prevent wheezing episodes in infants [42]. Single doses of long-acting $\beta$-agonists (LABAs) provide at least $12 \mathrm{~h}$ of bronchodilatation in asthmatic school-aged children. Bronchodilator and protective effects of single doses of LABA have been documented in children of preschool age and older. LABA for daily maintenance treatment in asthmatic children who remain symptomatic despite conventional doses of ICS is widely advocated and practised (step 3 of GINA guidelines) [30] but insufficiently supported by literature and debated $[10,43,44]$. Existing studies refer to highly selected populations at the severe end of the disease spectrum. A recent Cochrane review concludes that there is insufficient data to make firm conclusions on the use of LABA for preschool and school-aged children, the starting dose of ICS to which LABA could be added, the use of single versus two devices for administering combination therapy and the preferred type of LABA [45]. As-needed use of LABA plus ICS combination therapy on top of a low fixed dose has shown added benefit compared with daily fixed dose use in a selected population of children aged 4 yrs and older [44, 46]. However, there is evidence that ICS alone may be more effective than an ICS and LABA combination [10]. The bronchodilator and bronchoprotective effects of LABAs in children become less during chronic use $[47,48]$. The use of LABAs has been associated with a small risk of (near) fatal asthma attacks in adults, and there is concern about an increased risk of exacerbations. Pharmacogenetic studies have not yet established the importance of polymorphisms in the beta-2-receptor gene for effectiveness, tachyphylaxis and side effects of SABA or LABA.

\section{Current marketing authorisation}

Salbutamol DPIs, breath-actuated and standard pressurised MDIs (pMDIs), and inhalation solution are indicated for the prevention and relief of bronchoconstriction in patients aged 4 yrs and older (dry powder 6 yrs and older) and for the prevention of exercise-induced bronchoconstriction in patients 4 yrs of age and older. The inhalation solution is indicated for the relief of bronchoconstriction in patients 2 yrs of age and older with acute bronchoconstriction. Terbutaline Turbohaler ${ }^{\mathrm{TM}}$ (AstraZeneca, London, UK) and injection is indicated for the prevention and reversal of bronchoconstriction in patients with asthma.

Salmeterol dry powder and pMDI is licensed for long-term, twice daily administration as an add-on treatment of reversible airways obstruction in patients with asthma, including those with nocturnal asthma, who are inadequately controlled on ICS. It is also licensed for prevention of exercise-induced asthma. Its use in children aged under 4 yrs is unlicensed.

Formoterol Turbohaler ${ }^{\mathrm{TM}}$ and pMDI is indicated for long-term, twice daily administration in the maintenance treatment of asthma and in the prevention of bronchoconstriction in adults and children 6 yrs of age and older, including patients with symptoms of nocturnal asthma. It is also indicated for the acute prevention of exercise-induced bronchoconstriction in adults and children 6 yrs of age and older when administered on an occasional, as-needed basis.

Current unlicensed and off-label use

SABAs, especially salbutamol, are widely used in children younger than 2-6 yrs of age, and for other indications other than asthma or asthma-like illnesses, including bronchiolitis, bronchiectasis, chronic cough, CF airway disease, bronchopulmonary dysplasia and chronic lung disease of prematurity. There is little or no evidence to support this off-label use [42, 49-51]. There is some evidence that LABA may be ineffective in young children [52].

\section{Important research questions}

1) What is the effect of adding daily LABA to ICS therapy in children whose asthma is not fully controlled when stratified for initial ICS dose? 2) What is the importance of airway reversibility as a criterion to start LABA therapy? 3) Are there advantages in using LABA combined with ICS instead of SABA for acute symptom relief [53]? This can be compared with the alternative approach of giving high doses of ICS to abolish all symptoms, but with the risk of side-effects [54]. 4) What are the effects of LABA in preschool children and infants, especially duration of bronchodilator effects, protective effects after single doses, and after long-term treatment? 5) Are there age- and phenotype-specific effects of $\beta 2$-receptor gene polymorphisms on the effects and side effects of SABA and/or LABA in children with asthma? 6) Is there improved efficacy and safety with levosalbutamol versus racemic mixture [55]?

\section{Other anti-inflammatory and immunosuppressive agents}

\section{Evidence base}

Even when existing therapies are used according to established guidelines, there remains a small group of children who require frequent or continuous oral steroids, for control of symptoms and to treat or prevent exacerbations: "difficult asthma". This may be because of misdiagnosis, comorbidity (such as vocal cord dysfunction syndrome) or nonadherence with ICS therapy, or it may represent true steroid-resistant asthma. Nonadherence represents a difficult management problem [16] and monthly doses of intramuscular triamcinolone have been used [56]. 
Other anti-inflammatory agents are sometimes used as steroidsparing agents in children with asthma or as an alternative to steroids where asthma is believed to be steroid resistant. These include azathioprine, cyclosporin and methotrexate. There are no randomised controlled trials of these agents in children. Where asthma is associated with a raised immunoglobulin $(\mathrm{Ig}) \mathrm{E}$ level $\left(30-700 \mathrm{IU} \cdot \mathrm{mL}^{-1}\right)$, then the monoclonal anti-IgE agent omalizumab may be administered.

\section{Current marketing authorisation}

Omalizumab is licensed, as an add-on therapy, for severe persistent asthma, with frequent symptoms and exacerbations. For children aged $6-<12$ yrs of age, the drug is licensed where the $\mathrm{IgE}$ level is between 30 and $1,300 \mathrm{IU} \cdot \mathrm{mL}^{-1}$ and for those $>12$ yrs the drug is licensed for $\operatorname{IgE}$ between 30 and $700 \mathrm{IU} \cdot \mathrm{mL}^{-1}$.

Intramuscular triamcinolone is licensed for use in asthma in children over 6 yrs of age.

\section{Current unlicensed and off-label use}

The use of azathioprine, cyclosporine, methotrexate and other anti-inflammatory or immunosuppressive agents in children with asthma is off label and may be associated with significant toxicity.

\section{Important research questions}

Further studies of the small group of children with difficult asthma would be assisted by establishing a European registry and the careful phenotyping of children. This would allow trials of anti-inflammatory and immunosuppressive agents to be conducted only in those children who might benefit from these therapies. A registry would also increase the chances of achieving sufficient statistical power in clinical trials to confirm or exclude meaningful clinical benefit.

\section{Acute severe asthma}

\section{Evidence base}

In acute severe asthma there is severe airflow obstruction, which may lead to respiratory failure, requiring mechanical ventilation. All children should receive oxygen. The early use of systemic steroids shortens the duration of admission and reduces relapse [57]. $\beta$-agonists may be administered intermittently or continuously but current evidence supports continuous use [58]. Ipratropium bromide added to $\beta$-agonist reduces admissions and improves lung function [59]. Failure of inhaled treatment requires addition of intravenous bronchodilators including i.v. $\beta$-agonists [60], aminophylline [61] and, recently, magnesium sulfate [62]. Subcutaneous or i.m. adrenaline is necessary in near arrest or arrest situation following anaphylaxis [63]. Ketamine does not provide an incremental benefit to standard therapy [64]. Heliox, a combination of oxygen and helium at typical ratio of 40:60, shows promise in reducing intubation [65]. Noninvasive positive pressure ventilation may allow time for maximal benefit to be seen from pharmacotherapy.

\section{Current marketing authorisation}

Ipratropium is licensed for use in infants and children of all ages. In children aged under 6 yrs it is licensed for administration no more frequently than every $6 \mathrm{~h}$. Currently no i.v. dose is licensed for use in children. Aminophylline is licensed in children over 6 months of age. Adrenaline is licensed for i.m. use, in anaphylaxis, for infants and older children. Heliox is unlicensed.

\section{Current unlicensed and off-label use}

Intravenous use of salbutamol in children is off label. Magnesium sulfate is licensed for i.v. use in magnesium deficiency but not for acute severe asthma.

\section{Important research questions}

1) What is the effect of nebulised magnesium in acute severe asthma? There is currently one ongoing clinical trial [66]. 2) What is the role of i.v. montelukast in severe asthma in children? 3) What is the role of heliox in preventing intubation? 4) Does the use of dornase alfa reduce mucous plugging in ventilated patients?

\section{CYSTIC FIBROSIS \\ Therapies for use in children identified by newborn screening \\ Evidence base}

Newborn screening allows early management of malabsorption, with improved growth in infants with CF [67], and might allow early intervention against infection and bronchiectasis. Bronchoalveolar lavage at 3 months of age in infants with $\mathrm{CF}$ shows Staphylococcus aureus in $14(31 \%)$ out of 45 [68]. However, prophylactic antibiotic use in infants is controversial. A Cochrane review showed less $S$. aureus with prophylaxis but no clinical benefit [69]. Some studies have suggested more Pseudomonas aeruginosa with prophylaxis [70, 71].

Other treatments which could be evaluated in screened infants include dornase alfa [72] and hypertonic saline (see section on mucolytics) [73]. A small single-centre study to assess the effect of dornase alfa on lung function and high-resolution computed tomography (HRCT) is currently under way in Columbus, $\mathrm{OH}$, USA [74].

\section{Current unlicensed and off-label use}

Flucloxacillin is licensed in children aged less than 2 yrs in respiratory infection, but prophylactic use may be off label. Dornase alfa is licensed for use in CF patients with forced vital capacity $(\mathrm{FVC})>40 \%$ predicted and aged over 5 yrs. Use in young children is off label.

\section{Important research questions}

Newborn screening for $\mathrm{CF}$ has been introduced in many parts of the EU. Techniques such as HRCT scan [75] and infant lung function $[76,77]$ may be useful outcome measures for clinical trials. A number of research studies are ongoing or planned.

\section{Planned studies}

1) Infant Pulmozyme Study (Australia, USA and Europe): this randomised controlled trial will compare the use of dornase alfa and placebo in screened infants. Primary outcome: HRCT score at 2 yrs.

2) Infant Study of Inhaled Saline (ISIS): a trial of nebulised hypertonic saline in infants with CF will shortly commence enrolment [78].

Meetings to discuss trials linked to newborn screening in CF have been held, under the auspices of the ERS, in Leuven, 
Belgium (February 2007) and Stockholm, Sweden (September 2007). A consensus conference was convened by the European CF Society in March 2008.

\section{Suggested studies}

A large randomised controlled trial should address the question "Does prophylactic flucloxacillin versus placebo improve respiratory outcome in screened infants with CF?"

\section{Gastrointestinal interventions for CF}

Evidence base

Improved nutrition in people with $\mathrm{CF}$ is associated with improved lung function and survival $[79,80]$. Most people with CF have pancreatic exocrine insufficiency, with malabsorption and steatorrhoea, and require pancreatic enzyme replacement therapy (PERT). Use of high doses of PERT (particularly high lipase formulations) may be associated with fibrosing colonopathy [81]. There have been no reported cases following UK guidelines to reduce the daily intake of lipase to 10,000 units $\cdot \mathrm{kg}^{-1}$. Acid-resistant preparations of PERT have greatly improved effectiveness [82] and some new PERT preparations generate an alkaline environment in the small bowel [83]. PERT may work more effectively if gastric acidity is reduced (for example with a proton pump inhibitor); however, a systematic review did not show long-term benefit [84]. ALTU135 (a microbially derived PERT) is in phase 3 clinical trials [85]. Distal ileal obstruction syndrome is a serious complication of $\mathrm{CF}$ [86]. Standard therapy is gastrografin (or purgatives such as picolax) given either orally or by enema [87]. There is no evidence base for this therapy or for alternative treatments, such as lactulose or $N$-acetylcysteine. Oral calorie supplements are frequently used to improve nutrition in $\mathrm{CF}$, but without evidence of long-term benefit. The role of these preparations in the acute situation has not been adequately assessed [88, 89]. Supplementation of fat-soluble vitamins $\mathrm{A}, \mathrm{D}$ and $\mathrm{E}$ is a standard recommendation for children with $\mathrm{CF}$, although the evidence base is poor [90]. The situation with respect to vitamin $\mathrm{K}$ is even less clear, in particular with respect to the impact on long-term bone health [91, 92].

\section{Current unlicensed and off-label use (gastrointestinal drugs)}

The current licensing arrangements are summarised in table 1.

\section{Important research questions}

1) What is the most appropriate PERT for children with CF to promote normal growth? 2) What is the most appropriate treatment for distal ileal obstruction in children with $\mathrm{CF}$ ? 3) Does the addition of a drug to reduce gastric acid improve

TABLE 1 Current unlicensed and off-label use of gastrointestinal drugs

Drug type Specific drug Licensing arrangements

PERT

\section{Oral calorie supplements}

Drugs to reduce gastric acid

Treatment for DIOS

\section{Sodium bicarbonate}

Laxatives

Fat soluble vitamins

Motility agents

Taurine
Pancreatin, for example

Creon $10,000^{\mathrm{TM}}$ (Solvay, Southampton, UK)

Creon Micro ${ }^{\text {TM }}$ (Solvay, Southampton, UK)

Nutrizym $10^{\text {TM }}$ (Merck Serono, Feltham, UK)

Pancrex $^{\text {TM }}$ (Paines and Byrne, Staines, UK)

High-strength preparations

Different licensing arrangements (ACBS)

Omeprazole

Lansoprazole

Ranitidine

Cimetidine

Gastrografin

N-Acetylcysteine

Lactulose

Bisacodyl

Docusate

Movicol $^{\mathrm{TM}}$ (Norgine, Harefield, UK)

Vitamin E suspension

Multivitamin drops

Domperidone
Pancreatic insufficiency in children of all ages

Pancreatic insufficiency in children of all ages

Children aged over 2 yrs

Children aged over 2 yrs (capsules in infants) Not licensed for children under 15 yrs with CF

Children aged over 3 yrs

Capsules and tablets not licensed in children except for severe ulcerating reflux oesophagitis (injection not licensed in children aged under $12 \mathrm{yrs}$ )

Not licensed for children

Oral not licensed in children aged under 3 yrs (injections not licensed in children aged under 6 months)

Not licensed in children aged under $1 \mathrm{yr}$

Licensed for uncomplicated meconium ileus (not specifically licensed for DIOS, but is licensed for "infants and young children")

Not licensed for use in children with CF

Not licensed

Licensed for children

Not licensed for children aged under 10 yrs

Not licensed for children aged under 12 yrs

Licensed for children aged 2 yrs and older

Licensed for children with CF (all age groups)

Licensed for children of all ages

Not licensed for children

Not licensed for children

PERT: pancreatic enzyme replacement therapy; DIOS: distal ileal obstruction syndrome; CF: cystic fibrosis; ACBS: Advisory Committee on Borderline Substances. 
PERT performance and enhance growth in children? 4) Should acutely ill children with CF receive oral calorie supplements to maintain growth? 5) When and how should children with CF receive vitamin $\mathrm{K}$ supplements?

\section{Rational use of antibiotics}

\section{Evidence base}

Pulmonary infection with $P$. aeruginosa is associated with a more rapid decline in lung function and increased mortality [93]. Initially, the organism is present in its planktonic form (antibiotic susceptible) but later the organism forms an adherent biofilm, which is impossible to eradicate. Most CF units therefore practice early eradication of $P$. aeruginosa when it first appears in respiratory secretions. Eradication regimens commonly use either nebulised tobramycin alone or a combination of oral ciprofloxacin and nebulised colistin. A Cochrane review of randomised controlled trials evaluating $P$. aeruginosa eradication found that patients randomised to nebulised tobramycin were less likely to have $P$. aeruginosa at 12 months [94]. A combination of oral ciprofloxacin and nebulised colistin was effective in reducing chronic infection with $P$. aeruginosa, over a 2-yr follow-up. There are insufficient data on the clinical benefit of any of the eradication strategies and no direct comparisons of regimens.

Therapy for chronic infection with $P$. aeruginosa has recently been reviewed by the US CF Foundation [95]. Antibiotics via inhalation are used to improve disease course in patients with chronic P. aeruginosa. Tobramycin solution for inhalation (28day on-off cycles) decreases pulmonary exacerbations and improves lung function [96]. Several other treatment regimens (including nebulised colistin) are used and were shown in a Cochrane review to improve lung function. The wide range of drugs and dosing regimens, however, limited the possibility of pooling the studies to evaluate the effect on exacerbations of respiratory infections [97].

Several studies examined the value of long-term oral azithromycin administration on disease course in CF patients. The largest placebo-controlled trial in patients with chronic $P$. aeruginosa infection showed that active treatment improved lung function and decreased the exacerbation rate [98]. The mechanism of action is unclear. Fewer exacerbations, but not improved lung function, were also seen in patients without chronic $P$. aeruginosa [99].

Chronic lung infection due to $P$. aeruginosa with periodic exacerbations is the hallmark of CF lung disease. Pulmonary exacerbations reduce survival and quality of life as well as incurring significant healthcare costs [100]. Rational antibiotic therapy is therefore needed. Conventional treatment of a pulmonary exacerbation includes antibiotics and intensive chest physiotherapy. Commonly, oral antibiotics are used first, based on the antibiotic sensitivities of organisms from a recent respiratory specimen, followed by i.v. antibiotics if the response is poor. A quinolone, such as ciprofloxacin, is the usual first line antibiotic. Chloramphenicol has been used as a second-line oral antibiotic, despite negative results on conventional sensitivity testing [101]. Few studies have evaluated the use of i.v. antibiotics against placebo. The two randomised controlled trials that have been undertaken are underpowered. One failed to show benefit from i.v. ceftazidime [102], whereas a second study found improved outcome for $P$. aeruginosa quantitative culture and lung function [103]. Indirect evidence that prompt treatment of pulmonary exacerbations is beneficial long term comes from epidemiological surveys [104].

Theoretically, resistance to antibiotics in $P$. aeruginosa may be avoided with a combination of two or more i.v. antibiotics. A Cochrane review did not demonstrate any significant difference between monotherapy and combination therapy in clinical outcomes but there was a nonsignificant increase in antibiotic resistance with monotherapy [105]. There is little evidence for the use of any one anti-pseudomonal antibiotic combination, though there are many underpowered trials. However, a randomised trial comparing meropenem versus ceftazidime (both combined with tobramycin) suggested that the improvement in forced expiratory volume in $1 \mathrm{~s}$ (FEV1) was more rapid with meropenem [106]. Most CF centres start oral antibiotics and move to i.v. therapy if oral drugs do not promptly improve the patient's symptoms. A Cochrane review found few studies and no evidence to show that oral or i.v. anti-pseudomonal antibiotics were superior [107]. Most centres give 2 weeks of i.v. treatment. Observational data shows that most clinical benefit is seen after 2 weeks [108]. A Cochrane review concluded that once and three times daily aminoglycoside administration are equally effective in the treatment of pulmonary exacerbations in CF [109]. A large randomised controlled trial showed less nephrotoxicity, particularly in children with once-daily dosing [110]. Paradoxically, antibiotic susceptibility does not relate to response to i.v. antibiotics in retrospective [111] or prospective [112] studies.

Some CF centres administer antibiotics electively at regular intervals. There is no evidence from randomised controlled trials that this approach is superior to symptomatic treatment [113]. Home treatment was less disruptive to patient's lives, though patients reported greater fatigue and the time to next antibiotic course may be shorter [114, 115].

\section{Current marketing authorisation}

Oral antibiotics

Ciprofloxacin is licensed in acute pulmonary exacerbations of CF associated with $P$. aeruginosa infection in children aged 517 yrs. Use in children aged under 5 yrs is off label.

Azithromycin has no specific indication for CF. Doses for children aged under 3 yrs in SPC.

\section{Nebulised antibiotics}

Tobramycin solution for inhalation is licensed for the longterm management of chronic pulmonary infection due to $P$. aeruginosa in CF patients aged 6 yrs and older. Use for eradication is off license.

Colistin is licensed for the treatment by inhalation of $P$. aeruginosa lung infection in patients with CF. Doses are given in the SPC for children aged under 2 yrs. Colistin is also licensed for i.v. use.

\section{Intravenous antibiotics}

The following are licensed for use in pulmonary infection in patients with CF. 1) Aztreonam: licensed from age 7 days. 2) Amikacin, ceftazidime, colistin, gentamicin: no lower age limit given in SPC 3) Tobramycin: no lower age limit given in 
SPC but caution advised in infants less than 6 weeks old. Once daily tobramycin use is recommended in UK national guidelines [116]. 4) Meropenem and imipenem: licensed from age 3 months. 5) Piperacillin-tazobactam combination: licensed from age 12 yrs. Hypersensitivity reactions are a problem with pipercillin.

\section{Important research questions}

Planned studies

TORPEDO CF (Trial of Optimal Therapy for Pseudomonas Eradication in CF) (UK): a large randomised controlled trial of $P$. aeruginosa eradication, comparing oral ciprofloxacin with i.v. antibiotics (both groups receive nebulised colistin).

\section{Ongoing studies}

ELITE (Early Inhaled Tobramycin for Eradication) (Europe): randomised controlled trial of 28 versus 56 days of nebulised tobramycin, with the primary outcome duration of eradication over a 27-month period. Preliminary results show no difference between regimens [117].

EPIC (Early Pseudomonas Infection Control) (USA): all participants receive initial nebulised tobramycin and oral ciprofloxacin. When $P$. aeruginosa is eradicated, participants are randomised to either a further five consecutive quarterly cycles of tobramycin ( 1 month of nebulised therapy in every 3 months) or treatment directed by bacterial culture, both for 18 months. Within each group, there will be further randomisation to oral ciprofloxacin or placebo.

Other studies: nebulised aztreonam lysine, for maintenance treatment of chronic pulmonary infection with $P$. aeruginosa, has recently undergone phase III trials. Dry powder preparations of colistin and tobramycin [118] have completed phase III trials. Another inhaled aminoglycoside, nebulised liposomal amikacin, is currently in phase II trials. Dry powder ciprofloxacin and levofloxacin solution for inhalation have undergone phase I studies.

\section{Suggested studies}

1) Is oral chloramphenicol effective in pulmonary exacerbations due to resistant organisms? 2) What is the optimal duration of therapy in CF patients with chronic P. aeruginosa and a pulmonary exacerbation? Time to next exacerbation should be the primary outcome variable and emergence of resistance and toxicity additional outcomes.

\section{Fungal infection and allergic bronchopulmonary aspergillosis}

\section{Evidence base}

Aspergillus fumigatus is ubiquitous in the environment and is the most frequently isolated fungus from CF airway samples [119]. It can cause allergic reactions in the CF airway, termed allergic bronchopulmonary aspergillosis (ABPA). Other disease manifestations (bronchitis, aspergilloma and invasive infection) are less common. Candida albicans colonisation of mucous membranes is frequent in CF patients but invasive disease is rare. There are no randomised trials of treatment for any of these rare conditions.

ABPA occurs in 2-14\% patients with CF [120]. Diagnostic criteria have been put forward by the CF Foundation consensus conference [119]. Even when using strict criteria, the diagnosis remains difficult as some of the symptoms of ABPA are nonspecific. The course of ABPA is typified by acute exacerbations, remissions during treatment and, in many patients, relapses after discontinuing therapy. Oral corticosteroids are the mainstay of treatment, although no controlled study compares the use of antifungal agents with a course of oral corticosteroids. A Cochrane review of antifungal therapies for ABPA in CF identified no randomised trials [121]. The sole evidence for efficacy of ABPA treatment comes from studies in asthmatic patients [121]. Trials in patients with CF are needed. In CF patients there is poor bioavailability of itraconazole, especially of itraconazole tablets [122]. Additional treatments have been assessed in a noncontrolled way, such as methylprednisolone pulse therapy [123], omalizumab [124] and voriconazole [125]. Voriconazole has a higher oral bioavailability but is expensive, with side-effects in up to $30 \%$ of patients. There is no evidence to support the use of ICS to treat ABPA but there are reports of adrenal suppression when inhaled steroids and itraconazole are combined [126].

\section{Current unlicensed and off-label use}

Itraconazole is not licensed for ABPA. Its use in children is not recommended unless the benefits outweigh the risks. Voriconazole is not licensed for ABPA, and is not licensed for children aged under 2 yrs. Prednisolone is licensed for the "...suppression of inflammatory and allergic disorders." In children, it should be used "...only when specifically indicated, in a minimal dosage and for the shortest possible time." Omalizumab is not licensed for ABPA.

\section{Important research questions}

1) An industry-sponsored trial of omalizumab for ABPA in $C F$ is underway. 2) What are the pharmacokinetic parameters of azole antifungals in CF? 3) Are antifungals effective (with or without prednisolone) in ABPA? 4) Is treatment beneficial in individuals sensitised to Aspergillus, but who do not have ABPA [127]?

\section{Mucolytics and drugs that restore airway surface liquid Evidence base}

Airway secretions in CF are highly viscous; however, classic mucolytics, such as $N$-acetylcysteine, have little effect. This may be due to the fact that CF mucus contains little mucin and is mainly composed of pus [128]. Inhaled dornase alfa breaks down neutrophil-derived DNA and reduces sputum viscosity. In a large randomised controlled trial, in patients with mild to moderate lung disease, dornase improved pulmonary function and reduced the number of pulmonary exacerbations [129]. The effect on pulmonary exacerbations is also seen in younger children [130].

Since airway surface liquid depletion is considered an important factor in CF pathophysiology, osmotically drawing water onto the airway surface by inhalation of a hypertonic substance could restore defective mucociliary transport. Hypertonic saline has been shown to improve hydration of the airway surface liquid layer and mucociliary clearance [131]. 16 controlled trials have been conducted evaluating the efficacy of hypertonic saline in patients with $\mathrm{CF}$, of which 11 were of sufficient quality to be included in a Cochrane review [132]. 
Only the study by ELKINS et al. [133] fulfils the criteria of a phase III trial including a sufficient number of patients. The authors performed a multicentre double-blind randomised controlled trial of $7 \%$ saline solution in CF patients over 12 months. This study included paediatric patients aged 6 yrs and older, and overall study drug effects were similar in both adults and children. A small but significant difference was found in absolute lung function (averaged over the treatment period) between the two groups and pulmonary exacerbations were significantly reduced. A direct comparison of hypertonic saline versus dornase alfa was conducted by SuRI et al. [134] who found a greater improvement in FEV1 with dornase but no difference in pulmonary exacerbations.

As lower airway deposition of hypertonic saline is likely to be better before significant mucus accumulation in the airways has occurred, and treatment with hypertonic saline may be most efficacious when initiated early in the disease process. However, data for efficacy in young children are still lacking. SUBBARAO et al. [73] studied the safety of hypertonic saline in infants and preschool children. They performed infant lung function testing in 13 infants with CF who received 7\% hypertonic saline as a single dose and found no significant change after $7 \%$ hypertonic saline, with cough (in four infants) the only adverse effect. Currently, a longer pilot study to assess the safety of multiple doses of $7 \%$ saline in infants is under way.

\section{Current unlicensed and off-label use}

Dornase alfa is licensed for CF patients with FVC $>40 \%$ predicted and aged over 5 yrs. PARI MucoClear ${ }^{\mathrm{TM}}$ (hypertonic saline $6 \%$ in 4 -mL ampoules) has a CE medical device license, not a drug license; therefore, manufacturers do not give specific details of how to use the product. It has been listed in the UK Drug Tariff since October 2008 and is prescribable (as a "device"). Other forms of hypertonic saline may be available elsewhere in the EU; check the prescribing regulations in the appropriate member state. The $7 \%$ rather than the $6 \%$ solution was used in the pivotal clinical trial [133].

\section{Important research questions}

1) Is nebulised hypertonic saline effective in young infants? A multicentre randomised controlled trial looking at the efficacy of nebulised hypertonic saline versus $0.9 \%$ saline in this age group will shortly commence enrolment (see also section entitled Therapies for use in children identified by newborn screening) [78]. 2) Is nebulised dornase alfa or hypertonic saline more effective in preventing pulmonary exacerbations?

\section{Novel antibacterials}

\section{Evidence base}

$P$. aeruginosa is present in the lungs of most patients with $\mathrm{CF}$, by the late teenage years [135]. Eradication of $P$. aeruginosa may be possible, when the organism is in its planktonic phase but is impossible when it has formed a biofilm (organisms plus an exopolysaccaride matrix). Within the biofilm, organisms communicate, via quorum sensing molecules which control biofilm maturation and virulence factor expression [136]. The biofilm also enables the organism to evade host defences and antibiotics. Once infection has become chronic, mucoid $P$. aeruginosa strains, which are antibiotic resistant, are found in the sputum. Patients may develop allergic sensitisation to antibiotics [137] or suffer cumulative adverse effects such as renal impairment (aminoglycosides) [138], which further limit the choice of antibiotic regimens. New treatment strategies are needed.

One strategy is to develop quorum-sensing inhibitors. Azithromycin produces clinical benefit in patients with CF and chronic infection with $P$. aeruginosa, in spite of having no direct bacteriocidal or bacteriostatic action against this organism and it may inhibit biofilm formation. A "nutriceutical" garlic extract has been shown to inhibit quorum sensing in vitro, increasing biofilm susceptibility both to phagocytosis and to the antibiotic tobramycin, as well as improving the clearance of pulmonary infection with $P$. aeruginosa in a mouse model [139].

Another promising "nutriceutical" is the aminoacid glutamine. Parenteral glutamine supplements decrease mortality in a mouse model of pneumonia with $P$. aeruginosa from $75 \%$ to $29 \%$ [140]. In diseases, like CF, where there is a hypermetabolic state, glutamine requirements may increase, such that glutamine may become a conditionally essential amino acid [141]. Nebulised L-arginine has also been administered in CF, where a single dose has been shown to increase exhaled nitric oxide and FEV1 [142].

$P$. aeruginosa can cause infections such as chronic otitis externa in humans and in animals. A pilot study of a combination preparation of six anti-pseudomonal bacteriophages (BiovetPA) has been described in dogs with otitis externa [143]. The clinical condition improved in all the treated ears and bacterial counts fell in all but one. A clinical trial in human otitis externa is now ongoing and a trial of inhaled phage in CF is planned.

\section{Current unlicensed and off-label use}

There is no specific licensed indication for azithromycin in CF (see section on marketing authorisation for antiobiotics in CF). Glutamine and L-arginine are not licensed for use in CF.

\section{Important research questions \\ Ongoing studies}

The Garlic Against Pseudomonas (GAP) study: are quorumsensing inhibitors effective against $P$. aeruginosa in CF? A phase II randomised controlled trial of macerated garlic oil in CF has recently been completed [144].

\section{Planned studies}

Glutamine: are oral glutamine supplements in CF effective in reducing pulmonary inflammation in CF? A placebo-controlled randomised controlled trial is currently underway [145].

Bacteriophages: are bacteriophages effective in pulmonary infection with $P$. aeruginosa in CF?

\section{Potential studies}

Is azithromycin an effective quorum-sensing inhibitor in CF?

\section{Anti-inflammatory therapy}

CF lung disease is characterised by a vicious cycle of infection, inflammation and lung damage. Most patients with CF will ultimately die from respiratory failure. Anti-inflammatory therapy might reduce the inflammatory part of this cycle. A systematic review has shown that oral prednisolone, administered alternate daily, is associated with an improvement (or a 
lesser decline) in lung function but at the expense of impaired linear growth in children and other steroid-related side-effects [146]. A trial of withdrawal of inhaled steroids has shown that these drugs confer no benefit in terms of time to pulmonary exacerbation or lung function for most patients [147]. Nonsteroidal anti-inflammatory drugs (NSAIDs) in CF (primarily high-dose ibuprofen) can slow the decline in lung function. However, a systematic review showed that the effects of NSAIDs on other outcomes, such as pulmonary exacerbations, were inconsistent between studies [148]. Studies have had long follow-up periods (up to $4 \mathrm{yrs}$ ). There is a narrow therapeutic window with ibuprofen, requiring monitoring of plasma levels.

\section{Current unlicensed and off-label use}

Prednisolone is licensed for the "...suppression of inflammatory and allergic disorders." In children, it should be used "...only when specifically indicated, in a minimal dosage and for the shortest possible time."

ICS use in cystic fibrosis is off label and may expose children to adverse effects due to systemic absorption, e.g. when combined with itraconazole (see evidence base section for fungal infection and ABPA in cystic fibrosis).

Ibuprofen is not licensed treatment of pulmonary inflammation in $\mathrm{CF}$.

\section{Important research questions}

What is the incidence of adverse effects with long-term use of NSAIDs in CF? A large cohort study could provide additional important safety data.

\section{PRIMARY CILIARY DYSKINESIA \\ Evidence base}

A literature search using the terms "primary ciliary dyskinesia" or "immotile cilia syndrome" or "Kartagener's syndrome", limited to humans, the English language, and randomised controlled or clinical trials yielded 13 hits, of which only four were even remotely relevant to medications for children [149-152]. Of these, two were for experimental therapies directed at the underlying abnormality (an acute study of arginine in adults [150], and one of uridine- $5^{\prime}$ triphosphate, with patients average age 34 yrs, youngest 14 yrs [151]). One study explored a treatment now widely considered obsolete, $\mathrm{N}$-acetylcysteine, and showed no effect in primary ciliary dyskinesia (PCD) [152]. The sole study of possible clinical relevance showed that, in 19 children, regular salbutamol administered over a 6-week period had neither a helpful nor beneficial effect in terms of spirometry, or bronchial responsiveness [149]. It is, however, questionable whether anyone would want to prescribe $\beta_{2}$-agonists on a regular basis in this condition. This remains the only randomised controlled trial in children with this condition. A previous study showed that acute bronchodilatation to exercise was superior to that of $\beta_{2}$-agonist [153]; exercise was not a comparator in the above study. There are a few anecdotal reports of benefit for dornase alfa in PCD [154-156]. The clinical features of PCD have been reviewed recently [157]. For the most part, clinical management is based on protocols for $\mathrm{CF}$, which are themselves often not evidence based. The danger of this approach is indicated by the very different responses to recombinant human DNase in CF (beneficial [129]) and non-CF bronchiectasis (valueless, possibly even harmful [158]). A regimen of regular culture of respiratory secretions and aggressive antibiotic therapy for positive cultures may arrest the decline in lung function, however, this approach is supported only by observational data [159]. Thus there is a wide open field for the study of PCD.

\section{Current unlicensed and off-label use}

No medications are currently licensed for use in PCD.

\section{Important research questions}

1) Which antibiotics, by what route and in what doses, should be used for Haemophilus influenzae, S. aureus and P. aeruginosa? 2) Is there a role for modulation of the inflammatory response in PCD and if so, with what? 3) Are macrolides as useful in PCD as they are in CF $[98,99,160,161]$ ? 4) Is any mucolytic therapy useful in PCD, e.g. hypertonic saline? 5) What is the best treatment for chronic rhinitis in PCD? 6) What is the best treatment for chronic otorrhoea, in particular after tympanostomy tube insertion?

\section{MANAGEMENT OF COMMUNITY-ACQUIRED PNEUMONIA IN CHILDREN Evidence base}

The incidence of community-acquired pneumonia (CAP) has been based on population studies done in the 1970s and 1980s; 35-40 per 1,000 in children less than 5 yrs old, about 20 out of every 1,000 in 5-10 yr olds and about 10 in 1,000 in children aged over 10 yrs, in western countries [162, 163]. Half of the children aged under $5 \mathrm{yrs}$, but $<10 \%$ of those older than 5 yrs have needed hospital care [163]. Respiratory viruses, especially RSV and rhinoviruses, either alone or in combination with bacteria, are the most common aetiological agents of CAP in children under 2 yrs old. Mycoplasma pneumoniae infections are common from the age of 5 yrs and Chlamydia pneumoniae infections from the age of $10 \mathrm{yrs}$ onwards. Streptococcus pneumoniae is the most important causative agent in paediatric pneumonia at all ages and in both inpatients and outpatients. The role of S. pneumoniae as the most common cause of CAP may change if immunisations with pneumococcal conjugate vaccine are universally implemented. Recent reports from the USA show a substantial fall in medical visits for pneumonia after starting vaccinations [164].

In European countries, pneumococcal penicillin resistance varied from $<5 \%$ to $>60 \%$ (intermediate and highly resistant strains combined) in 1999-2000, and the highest figures were detected in France, Spain and Hungary [165]. Pneumococcal macrolide resistance varied from $<5 \%$ to $50 \%$, and the highest figures were detected in France, Italy and Hungary [165]. Both penicillin and macrolide resistance figures were highest in infants under 2 yrs of age, and the figures decreased when the children grew older [166]. Many studies agree that high rates of antibiotic prescribing in children lead to antibiotic resistance in the community: high consumption of broad-spectrum $\beta$-lactams leads to penicillin resistance and further to multi-resistance, and high consumption of macrolides (especially the second-generation agents) to macrolide resistance [167]. The development and spread of antibiotic resistance in pneumococci are crucial when considering treatment of pneumonia in children. However, the spread of resistant pneumococci has also taken place in 
countries with low usage of antibiotics, as seen in the increase of macrolide-resistant strains in Norway [168].

The evidence indicates that clinical and radiological findings cannot be used to reliably discriminate between CAP of viral, bacterial or atypical aetiology [169, 170]. Rapid isolation of bacterial pathogens and the prescription of appropriate narrow-spectrum antibiotics are not feasible in most circumstances. Viral aetiology can be identified rapidly and helps prevent inappropriate prescription of antibacterials in mild cases. However, mixed infections are common and without reliable rapid diagnostic tests that can exclude bacterial pneumonia, empirical treatment remains necessary. Many clinical trials for CAP in children have been conducted as comparative studies comparing different antibiotic regimens, and these represent an important assessment of different empirical treatments. The Cochrane library contains two recent reviews relevant to the treatment of pneumonia in children. The first is a comprehensive review of the evidence for antibiotic treatments for CAP in children [171]. The second review addresses, specifically, the evidence for use of oral antibiotics versus parenteral antibiotics for severe pneumonia in children [172].

Findings from antibiotic trials for the treatment of ambulatory patients with CAP suggest oral amoxicillin is superior to oral co-trimoxazole and procaine penicillin superior to oral cotrimoxazole [171]. Co-amoxyclav may outperform amoxicillin (though evidence is limited) [171]. A 3-day course of amoxicillin may be adequate for treatment and double-dose amoxicillin infers no advantage over standard dose therapy. No difference in treatment outcomes were seen for comparisons between azithromycin and amoxicillin, azithromycin and co-amoxiclav, azithromycin and erythromycin, clarithromycin and erythromycin, and between cefpodoxime and co-amoxyclav. This does not necessarily mean these treatments are equivalent as studies may be underpowered to detect small differences in effect.

Findings from antibiotic trials for treatment of hospitalised patients with severe CAP suggest a combination of penicillin and gentamicin is superior to parenteral chloramphenicol [173]. Procaine penicillin may be as effective as cefuroxime [174].

Of great interest are studies comparing injectible penicillins with oral amoxicillin for treatment of hospitalised patients with severe pneumonia $[172,175]$. These suggest similar failure rates at 48 h, 5 days and 14 days for both treatments and have important implications particularly in developing countries where facilities for inpatient care may be limited.

\section{Current unlicensed and off-label use}

\section{Antibiotics usually administered orally}

Amoxicillin, cefpodoxime, clarithromycin, co-amoxyclav and erythromycin are licensed for infants and older children for treatment of respiratory tract infection. In the case of chloramphenicol, i.v. and oral preparation is licensed in the EU. According to the SPC, it "...should not be used for trivial infections due to the possibility of severe blood dyscrasias..." Co-trimoxazole is licensed for respiratory tract infections in children from age 6 weeks. Azithromycin is licensed for CAP but not in children under 6 months of age.
Antibiotics usually administered parenterally

Benzyl penicillin, cefuroxime and gentamicin are licensed for infants and older children for treatment of respiratory tract infection. Procaine penicillin is not licensed in the EU.

\section{Important research questions}

1) Are new antibacterials of equivalent efficacy to existing regimens? 2) Do new agents have advantages such as an improved side-effect profile, narrow-spectrum cover, ease of use or cost? 3) Which paediatric patients need treatment with antibacterials? 4) Are new sensitive rapid diagnostic tests for bacterial or atypical aetiology effective in clinical practice? 5) Which children need hospital admission? 6) What is the optimum duration of treatment? 7) What are the trends in resistance patterns?

\section{PLEURAL INFECTION IN CHILDREN \\ Evidence base}

Empyema an uncommon complication of bacterial pneumonia in children, defined as the presence of pus in the pleural cavity. Recent reports suggest that the prevalence is increasing in both the UK [176] and the USA [177]. The reasons for this are unclear but the introduction of routine infant vaccination with sevenvalent pneumococcal conjugate vaccine has not reduced this trend [178]. Death is extremely rare in children, in contrast to adult empyema which has an estimated mortality of 20\% [179]. Unlike adults, children with empyema are almost always healthy prior to illness onset. Decisions on the best treatment should therefore be based on data from studies on children [180].

There is universal agreement that antibiotics should be given promptly, intravenously, and in high dosage [180]. There is considerable controversy about additional treatment and a number of options should be considered. An analysis of 54 observational studies of treatment with antibiotics (alone or in combination with simple chest drainage) showed that treatment was successful in $75-80 \%$ but necessitated a prolonged hospital stay [181]. Fibrinolytics, administered through small intrapleural catheters, may be added to this regimen to augment drainage. In a randomised controlled trial of urokinase versus placebo, the primary outcome measure was length of hospital stay postintervention and was significantly in favour of urokinase (7.4 versus 9.5 days) [182]. In contrast, a randomised controlled trial of streptokinase versus placebo found no difference in clinical and sonographic outcome [183]. A randomised comparison of urokinase versus video-assisted thoracosopic surgery (VATS) found no difference in clinical outcome but showed that urokinase was a more economic treatment option [184]. Some centres advocate proceding to primary surgery either by an open debridement or by VATS [185].

\section{Current unlicensed and off-label use}

Alteplase, dornase alfa, streptokinase and urokinase are not licensed for intrapleural use.

All the antibiotics commonly used for the management of empyema are licensed for the treatment of lower respiratory tract infection in children (see section on CAP in children).

\section{Important research questions \\ Antibiotics}

Do antibiotics penetrate into the pleural space when given intravenously or orally? 


\section{Intrapleural drugs}

Is alteplase (tissue plasminogen activator) effective in empyema? (Alteplase is used in North America for empyema. Evidence is from retrospective reviews [186, 187], rather than randomised controlled trials).

Is a single-chain urokinase-type plasminogen activator a more effective fibrinolytic drug (resistant to inactivation by plasminogen activator inhibitors)?

Is dornase alfa effective in paediatric empyema? Dornase alfa, in combination with a fibrinolytic, is currently subject to a large randomised controlled trial in adults in the UK and it has potential for further investigation in childhood empyema [188].

\section{Preventative strategies}

Is universal immunisation with a pneumococcal vaccine containing a wider range of relevant serotypes an effective preventative strategy? The effectiveness of such a strategy could be studied through enhanced surveillance of pneumococcal empyema throughout Europe.

\section{CONGENITAL ABNORMALITIES OF THE TRACHEOBRONCHIAL TREE AND LUNG PARENCHYMA \\ Evidence base}

Congenital abnormalities of the tracheobronchial tree and lung parenchyma include the following conditions: tracheomalacia and bronchomalacia; tracheal and bronchial stenosis; bronchogenic and parenchymal cysts; pulmonary agenesis, aplasia and hypoplasia; congenital lobar emphysema; congenital cystic adenomatoid malformation (CCAM); pulmonary sequestration; and other rare abnormalities.

The pathogenesis of these conditions is complex and individually they are rare. However, it is estimated that the combined birth prevalence of tracheomalacia and bronchomalacia is at least one in 2,100 [189]. The most common presenting symptoms are nonspecific, ranging from severe dyspnoea and respiratory failure to recurrent wheeze and respiratory tract infection. There may be diminished exercise tolerance, sometimes resembling asthma. No randomised trials have addressed the most important complications of these disorders, being recurrent lower airways infections and dyspnoea (which, in the case of tracheomalacia or bronchomalacia, may be due to collapse of large airways during expiration). Airway collapse or narrowing may impair mucociliary clearance, leading to secondary infection. Treatment is surgical for some congenital lung abnormalities, such as CCAM, bronchogenic cysts, and some cases of lobar emphysema and sequestration. However, empirical drug treatment is used in many patients, with the broad aim of preventing secondary infection and overcoming atelectasis due to retained secretions. Hence mucolytic, bronchodilator and antibiotic medication have all been tried with or without physiotherapy.

\section{Current unlicensed and off-label use}

Routine treatment in many countries and centres consists of the control of recurrent bacterial infections using antibiotic therapy and chest physiotherapy. Studies on the efficacy and adverse effects of prophylactic antibiotic treatment are lacking. Prophylactic antibiotic treatment for this patient category is off label.
The efficacy of bronchodilator drugs on relieving symptoms may be age dependent and disease specific but has not been addressed. The use of bronchodilators may be unhelpful in tracheomalacia or bronchomalacia because they may exacerbate large airway collapse [190, 191]. Treatment with inhaled $\beta_{2}$-agonists for tracheomalacia or bronchomalacia is off label.

Children with both asthma and tracheomalacia pose a therapeutic challenge because lung deposition of ICS may be reduced. ICS are being prescribed to some of these patients off label.

Various mucolytic or supposedly mucolytic drugs are being administered to patients but efficacy, dosage and safety have not been studied in randomised controlled trials. In the literature, there is very little evidence of efficacy of $\mathrm{N}$ acetylcysteine, dornase alfa and hypertonic saline, or of their safety, in this patient category [192].

\section{Important research questions}

1) What is the efficacy, safety and cost-effectiveness of inhaled dornase alfa in this patient group (number of antibiotic courses and exacerbations as outcome measures)? 2) What is the efficacy, safety and cost-effectiveness of inhaled hypertonic saline in patients with tracheomalacia or bronchomalacia on the course and prevention of lower respiratory infections? How does efficacy compare to dornase alfa? 3) What is the optimal prophylactic antibiotic treatment for the prevention of lower respiratory infections in patients with a tendency to airways collapse (e.g. tracheomalacia) or who are otherwise vulnerable to infection (e.g. CCAM)? 4) How should asymptomatic malformations be treated?

\section{NEUROMUSCULAR DISEASES, SLEEP DISORDERS AND THORACIC MALFORMATIONS IN CHILDREN Pharmacotherapy for respiratory complications in children with neuromuscular diseases and thoracic malformations}

Evidence base

Neuromuscular diseases (NMDs) comprise: cerebral palsy, muscular dystrophies, congenital and metabolic myopathies, disorders of the neuromuscular junction, peripheral neuropathies and anterior horn cell disease (spinal muscular atrophies). Although the origins of these disorders are entirely different, the respiratory symptoms and morbidity overlap to a large extent. The respiratory consequences of NMD are: a decrease in pulmonary development in early onset diseases, a decrease in cough efficiency and mucociliary clearance (largely related to expiratory muscle failure), respiratory infections, acute respiratory failure and sleep-disordered breathing (SDB) (inspiratory muscle failure, day time respiratory failure, kyphosis and scoliosis). In addition, in cerebral palsy patients, oropharyngeal motor problems, gastro-oesophageal reflux disease and chronic aspiration of food or secretions are encountered in a large majority of children. Respiratory symptom occurrence may sometimes be reversed, delayed or slowed down by specific treatments of NMD. Such treatments are not targeted on the respiratory function, but on muscular improvement, which can be assessed by different muscular tests and respiratory outcome measures. Muscular improvement can be achieved using acetylcholinesterase inhibitors, licensed for congenital myasthenic syndromes (CMS). There is solid evidence for efficacy of glucocorticosteroids on muscular 
improvement for Duchenne muscular dystrophy [193]. Surgical improvement of thoracic malformations are only partly effective, if at all. The most frequent and most common complications of these diseases are recurrent and/or prolonged lower airways infections. However, no studies are available that investigated management of these infections.

\section{Current unlicensed and off-label use}

1) There is considerable overlap with the off-label use of drugs in children with congenital pulmonary abnormalities. Use of antibiotic prophylaxis in patients with NMD is off label. 2) Use of mucoactive drugs in patients with NMD is off label. 3) Unlicensed drugs for CMS are: quinidine or fluoxetine, 3,4diaminopyridine, acetazolamide and ephedrine. 4) There is some weak evidence for the efficacy of $\beta_{2}$-agonists, resulting in some muscle strength enhancement in muscular dystrophy [194, 195] and spinal muscular atrophy [196]. 5) Valproate is prescribed for muscle strength enhancement to some patients with spinal muscle atrophy based on a small study in adults [197]; no paediatric data are available. 6) In cerebral palsy, the use of hyoscine patches, for drying secretions, and intraparotid botulinum toxin are off label. 7) Use of bronchodilators to facilitate coughing and improve mucociliary clearance is off label.

\section{Important research questions}

1) What are the efficacy, safety and adverse effects of antibiotic prophylaxis in children with NMD? 2) What are the efficacy, safety and adverse effects of muco-active drugs in children with NMD? 3) Is muscle strength enhanced by the use of $\beta_{2^{-}}$ agonists in patients with NMD? 4) Is muscle strength enhanced by the use of quinidine or fluoxetine, 3,4-diaminopyridine, acetazolamide and ephedrine in patients with CMS?

\section{Pharmacotherapy for respiratory complications in children with sleep disorders}

\section{Evidence base}

SDB is a spectrum of disorders, ranging from primary snoring to severe obstructive sleep apnoea (OSA). Primary snoring may affect $10-25 \%$ of children aged $3-12$ yrs, and $10 \%$ of these children may have OSA. OSA is most often due to enlarged adenoids and tonsils, but other causes of upper airway obstruction, such as facial or maxillofacial deformities, structural abnormalities of the upper airway such as laryngomalacia or tracheomalacia, cystic hygroma, or various diseases such as Prader-Willi syndrome, or mucopolysaccharidosis, may also cause OSA. Adenotonsilectomy may be effective in SDB related to adenotonsilar hypertrophy. Noninvasive ventilation may be needed where surgery is ineffective or inappropriate. Ventilatory support, preferentially noninvasive, is the treatment of choice in case of severe SDB, but several medications, such as local steroids [198], leukotriene antagonists [199] or both [200] have been evaluated in children with moderate SDB. In some diseases, specific treatments have been assessed. In children with mucopolysaccharidosis I, laronidase was shown to be effective in a randomised trial, resulting in general muscle strength enhancement and improvement of sleep apnoea/ hypopnoea in more severely affected patients [201].

\section{Current unlicensed and off-label use}

Use of montelukast or nasal steroids for SDB is off label; however, these compounds may be prescribed because of allergic rhinitis and may improve SDB because of efficacy on allergic rhinitis symptoms.

\section{Important research question}

Are nasal steroids and montelukast effective in SDB? Large randomised controlled trials are needed.

\section{PHARMACOTHERAPY FOR RESPIRATORY TRACT INFECTIONS IN CHILDREN WITH IMMUNOLOGICAL DISORDERS}

\section{Evidence base}

This heterogeneous group of patients include those with neutrophil disorders, antibody deficiencies, chemotherapyinduced prolonged neutropenia, common variable immunodeficiencies, chronic granulomatous disease and others. These are rare disorders, but are all associated with considerable morbidity and mortality. The most important threats to these patients are respiratory tract infections, progressive damage to lungs and airways, and respiratory failure and death. Chronic pulmonary damage can be noticed both in children experiencing clinically manifest respiratory tract infections as well as in asymptomatic children [202]. Pathogens include bacteria, viruses and fungi. New treatment modalities are being developed, but mainly tested and carried out in adults. International randomised clinical trials have not been carried out consistently in the paediatric field, though it is obvious that they are much needed. Hence, evidence-based pharmacotherapy in these children is limited. Antibiotic prophylaxis are prescribed on a very large scale for this category of patients, but not evidence based. Similarly, administration of i.v. Igs is standard treatment, but evidence comes from cohort studies not from randomised controlled trials [203].

\section{Current marketing authorisation}

Human normal Ig solution is licensed for replacement therapy in congenital agammaglobulinaemia and hypogammaglobulinaemia, common variable immunodeficiency, severe combined immunodeficiency and IgG subclass deficiencies with recurrent infections.

\section{Current unlicensed and off-label use}

1) There is overlap with off-label usage in congenital pulmonary abnormalities and NMD (see information in the previous sections). 2) See section on CAP for the licensing status of antibiotics commonly used in the management of respiratory infection in children. 3) Prophylactic antibiotic treatment in the absence of symptoms is off label. 4) Administration of Igs is off label for most respiratory diseases in children. 5) Antifungal medication is, with the exception for liposomal amphotericin B and fluconazole, not licensed for use in children because of very limited data on safety, efficacy and dosage.

\section{Important research questions}

1) What is the most effective and safe antibiotic prophylaxis for subgroups of patients with specific immunological disorders? 2) Is the addition of antibiotic prophylaxis (directed against $S$. pneumoniae, $H$. influenzae, Moraxella catarrhalis and M. pneumoniae) to Ig replacement therapy in children with agammaglobulinemia, hypogammaglobulinemia or common variable immunodeficiency more effective in the prevention of chronic pulmonary 
damage than Ig treatment alone? 3) Is posaconazole superior to itraconazole as prophylactic agent to prevent invasive mould infections in children with acute myeloid leukaemia, severe aplastic anaemia and myelodysplastic syndrome, and after haemopoetic stem cell transplant [204]? 4) Is aerosolised liposomal amphotericin B [205] more effective than itraconazole, posaconazole or placebo in the prevention of invasive mould infections in neutropenic paediatric patients? 5) What is the tolerability and pharmacokinetics of posaconazole in children aged 8-16 yrs? 6) What is the efficacy of voriconazole monotherapy versus combination antifungal therapy consisting of voriconazole and anidulafungin (or caspofungin) in the treatment of invasive aspergillosis in children with neutrophil disorders?

\section{CONCLUSION}

We conclude that there is good evidence to guide some, but by no means all, drug treatment in children with asthma and cystic fibrosis. However, off-licence and off-label prescribing is prevalent. In other, less common respiratory conditions in children, off-licence prescribing is the rule and well-designed studies are urgently needed. Important research areas in asthma include the use of novel formulations and regimens, together with individualised prescribing, based on genotype and phenotype. In CF, new pancreatic enzyme and antibiotic formulations, together with drugs which modify the basic defect of $\mathrm{CF}$ are a major research area. Increasingly, studies will focus on screened infants and robust outcome measures for young children are needed. For children with CAP, evaluation of new antibacterials and treatment regimens (particularly for improvements in side-effect profile, ease of use or cost), together with assessment of new sensitive rapid diagnostic tests, are a priority. In children with pleural infection it is important to undertake studies of antibiotic penetration into the pleural space, evaluation of new fibrinolytics and enhanced pneumococcal surveillance. In PCD and children with congenital pulmonary abnormalities or NMDs, the use of drugs which are indicated for other conditions (e.g. dornase alfa or prophylactic antibiotics) is frequent but not evidence based, and may be harmful. Proper randomised controlled trials in these conditions are needed. In NMDs, drugs commonly used in other conditions may have a novel mechanism of action which needs further evaluation. In children with immune deficiency, welldesigned studies of antibiotic prophylaxis, Ig and antifungal drugs (including pharmacokinetics) are needed.

We have summarised the evidence for respiratory medicines in children and suggested important research priorities to help plug the evidence gap. There has never been a better time to answer important clinical questions about children's medicines, in order to improve safety and efficacy. We hope that this report of the evidence and our suggested research priorities for respiratory medicines in children will be a useful starting point for clinical researchers, the pharmaceutical industry, the paediatric committee of the EMEA, academic investigators and the lay public. From here on, new directions in future research can be determined to further improve respiratory health in European children.

\section{STATEMENT OF INTEREST}

Statements of interest for A.R. Smyth, P.J. Merkus, H. Bisgaard, K. de Boeck, P. Brand, A. Bush, J. de Jongste, M. Korppi, F. Ratjen, D. Spencer, A. Thomson, H. Vyas and A. Warris can be found at www.erj. ersjournals.com $/ \mathrm{misc} /$ statements.dtl

\section{ACKNOWLEDGEMENTS}

A.R. Smyth (Division of Child Health, University of Nottingham, Queens Medical Centre, Nottingham, UK) and P.J. Merkus (Dept of Paediatrics, Division of Respiratory Medicine, Children's Hospital, Radboud University, Nijmegen Medical Centre, Nijmegen, the Netherlands) edited the present report on behalf of the European Respiratory Society task force on pulmonary diseases seen in children and adults.

The other task force members and co-authors of this report, and their affiliations details, are as follows. A. Barbato: University of Padova, Padova, Italy; N. Beydon: Robert Debre Hospital, Paris, France; H. Bisgaard: Copenhagen University Hospital, Copenhagen, Denmark; K. de Boeck: University of Leuven, Leuven, Belgium; P. Brand: Princess Amalia Children's Clinic, Isala Klinieken, Zwolle, the Netherlands; A. Bush: Royal Brompton Hospital and Imperial College London, London, UK; B. Fauroux: Armand Trousseau Hospital and Pierre and Marie Curie University, Paris, France; J. de Jongste and M. Pijnenburg: Erasmus University Medical Centre, Rotterdam, the Netherlands; M. Korppi: Paediatric Research Centre, Tampere University and University Hospital, Tampere, Finland; C. O'Callaghan: University of Leicester, Leicester, UK; F. Ratjen: Hospital for Sick Children, University of Toronto, Toronto, ON, Canada; K. Southern: University of Liverpool, Liverpool, UK; D. Spencer: Newcastle upon Tyne Hospitals NHS Foundation Trust, Newcastle upon Tyne, UK; A. Thomson: John Radcliffe Hospital, Oxford, UK; H. Vyas: Nottingham University Hospitals NHS Trust, Nottingham, UK; A. Warris: Radboud University, Nijmegen Medical Centre, Nijmegen, the Netherlands.

\section{REFERENCES}

1 Conroy S, Choonara I, Impicciatore P, et al. Survey of unlicenced and off label drug use in paediatric wards in European countries. BMJ 2000; 320: 79-82.

2 Bush A. Evidence-based medicines for children: important implications for new therapies at all ages. Eur Respir J 2006; 28: 1069-1072.

3 National Health Service, National Institute for Health Research. Medicines for Children Research Network. www.mcrn.org.uk Date last accessed: May 12, 2009.

4 Lenney W, Boner AL, Bont L, et al. Medicines used in respiratory disease only seen in children. Eur Respir J 2009; 34: 531-551.

5 Brand PLP, Baraldi E, Bisgaard H, et al. Definition, assessment and treatment of wheezing disorders in preschool children: an evidence-based approach. Eur Respir J 2008; 32: 1096-1110.

6 Datapharm Communications Ltd. Electronic Medicines Compendium. http://emc.medicines.org.uk/ Date last accessed: May 12, 2009.

7 Ducharme FM. Inhaled glucocorticoids versus leukotriene receptor antagonists as single agent asthma treatment: systematic review of current evidence. BMJ 2003; 326: 621.

8 Townshend J, Hails S, McKean M. Management of asthma in children. BMJ 2007; 335: 253-257.

9 Baatenburg de Jong A, Brouwer AFJ, Roorda RJ, et al. Normal lung function in children with mild to moderate persistent asthma well controlled by inhaled corticosteroids. J Allergy Clin Immunol 2006; 118: 280-282.

10 Sorkness CA, Lemanske RF Jr, Mauger DT, et al. Long-term comparison of 3 controller regimens for mild-moderate persistent childhood asthma: the Pediatric Asthma Controller Trial. J Allergy Clin Immunol 2007; 119: 64-72.

11 Zeiger RS, Szefler SJ, Phillips BR, et al. Response profiles to fluticasone and montelukast in mild-to-moderate persistent childhood asthma. J Allergy Clin Immunol 2006; 117: 45-52.

12 Stempel DA, Pinto L, Stanford RH. The risk of hospitalization in patients with asthma switched from an inhaled corticosteroid to 
a leukotriene receptor antagonist. J Allergy Clin Immunol 2002; 110: 39-41.

13 Brand PLP. Inhaled corticosteroids reduce growth. Or do they? Eur Respir J 2001; 17: 287-294.

14 Agertoft L, Pedersen S. Effect of long-term treatment with inhaled budesonide on adult height in children with asthma. N Engl J Med 2000; 343: 1064-1069.

15 Todd GR, Acerini CL, Ross-Russell R, et al. Survey of adrenal crisis associated with inhaled corticosteroids in the United Kingdom. Arch Dis Child 2002; 87: 457-461.

16 McKenzie SA, Bush A. Difficult asthma in children. Thorax 2002; 57: 915-916.

17 Szefler SJ, Warner J, Staab D, et al. Switching from conventional to extrafine aerosol beclomethasone dipropionate therapy in children: a 6-month, open- label, randomized trial. J Allergy Clin Immunol 2002; 110: 45-50.

18 Von Berg A, Engelstatter R, Minic P, et al. Comparison of the efficacy and safety of ciclesonide $160 \mu \mathrm{g}$ once daily versus budesonide $400 \mu \mathrm{g}$ once daily in children with asthma. Pediatr Allergy Immunol 2007; 18: 391-400.

19 Kaditis AG, Winnie G, Syrogiannopoulos GA. Anti-inflammatory pharmacotherapy for wheezing in preschool children. Pediatr Pulmonol 2007; 42: 407-420.

20 Guilbert TW, Morgan WJ, Zeiger RS, et al. Long-term inhaled corticosteroids in preschool children at high risk for asthma. N Engl J Med 2006; 354: 1985-1997.

21 Murray CS, Woodcock A, Langley SJ, et al. Secondary prevention of asthma by the use of Inhaled Fluticasone propionate in Wheezy INfants (IFWIN): double-blind, randomised, controlled study. Lancet 2006; 368: 754-762.

22 Ermers MJJ, Rovers MM, van Woensel JB, et al. The effect of high dose inhaled corticosteroids on wheeze in infants after respiratory syncytial virus infection: randomised double blind placebo controlled trial. BMJ 2009; 338: b897.

23 Boluyt N, van der Lee JH, Moyer VA, et al. State of the evidence on acute asthma management in children: a critical appraisal of systematic reviews. Pediatr 2007; 120: 1334-1343.

24 Zhang L, Mendoza RA. Doses of systemic corticosteroids in hospitalised children with acute asthma: a systematic review. J Paediatr Child Health 2006; 42: 179-183.

25 Rodrigo GJ. Rapid effects of inhaled corticosteroids in acute asthma: an evidence-based evaluation. Chest 2006; 130: 1301-1311.

26 Lucas-Bouwman ME, Roorda RJ, Jansman FG, et al. Crushed prednisolone tablets or oral solution for acute asthma? Arch Dis Child 2001; 84: 347-348.

27 Fox GF, Marsh MJ, Milner AD. Treatment of recurrent acute wheezing episodes in infancy with oral salbutamol and prednisolone. Eur J Pediatr 1996; 155: 512-516.

28 Corneli HM, Zorc JJ, Mahajan P, et al. A multicenter, randomized, controlled trial of dexamethasone for bronchiolitis. $N$ Engl J Med 2007; 357: 331-339.

29 Panickar J, Lakhanpaul M, Lambert PC, et al. Oral prednisolone for preschool children with acute virus-induced wheezing. N Engl J Med 2009; 360: 329-338.

30 Global Initiative for Asthma (GINA). Global Strategy for Asthma Management and Prevention. National Heart, Lung, and Blood Institute, National Institutes of Health (USA) and World Health Organization, 2007. Available from www.ginasthma.org

31 Garcia Garcia ML, Wahn U, Gilles L, et al. Montelukast, compared with fluticasone, for control of asthma among 6- to 14-year-old patients with mild asthma: the MOSAIC study. Pediatr 2005; 116: 360-369.

32 US National Institutes of Health. ClinicalTrials.gov. www. clinicaltrials.gov / ct $2 /$ results? term $=$ asthma+and + inhaled + corticosteroids Date last accessed: May 12, 2009.
33 Knorr B, Franchi LM, Bisgaard H, et al. Montelukast, a leukotriene receptor antagonist, for the treatment of persistent asthma in children aged 2 to 5 years. Pediatr 2001; 108: E48.

34 Bisgaard H, Nielsen KG. Bronchoprotection with a leukotriene receptor antagonist in asthmatic preschool children. Am J Respir Crit Care Med 2000; 162: 187-190.

35 Hakim F, Vilozni D, Adler A, et al. The effect of montelukast on bronchial hyperreactivity in preschool children. Chest 2007; 131: 180-186.

36 Bisgaard H, Zielen S, Garcia-Garcia ML, et al. Montelukast reduces asthma exacerbations in 2- to 5-year-old children with intermittent asthma. Am J Respir Crit Care Med 2005; 171: 315-322.

37 Johnston NW, Mandhane PJ, Dai J, et al. Attenuation of the September epidemic of asthma exacerbations in children: a randomized, controlled trial of montelukast added to usual therapy. Pediatr 2007; 120: e702-e712.

38 Robertson CF, Price D, Henry R, et al. Short-course montelukast for intermittent asthma in children: a randomized controlled trial. Am J Respir Crit Care Med 2007; 175: 323-329.

39 Bisgaard H, Flores-Nunez A, Goh A, et al. Study of montelukast for the treatment of respiratory symptoms of post-respiratory syncytial virus bronchiolitis in children. Am J Respir Crit Care Med 2008; 178: 854-860.

40 US National Institutes of Health. ClinicalTrials.gov. http:// clinicaltrials.gov $/$ ct $2 /$ results?term $=$ montelukast\&pg $=1 \quad$ Date last accessed: May 12, 2009.

41 Walters EH, Walters J, Gibson $\mathrm{P}$, et al. Inhaled short acting $\beta_{2^{-}}$ agonist use in chronic asthma: regular versus as needed treatment. Cochrane Database Syst Rev 2003; 1: CD001285.

42 Chavasse RJ, Seddon P. Response to salbutamol by wheezy infants. Arch Dis Child 2004; 89: 796.

43 Verberne AA, Frost C, Duiverman EJ, et al. Addition of salmeterol versus doubling the dose of beclomethasone in children with asthma. The Dutch Asthma Study Group. Am J Respir Crit Care Med 1998; 158: 213-219.

44 Bisgaard $H$, Szefler S. Long-acting $\beta_{2}$ agonists and paediatric asthma. Lancet 2006; 367: 286-288.

$45 \mathrm{Ni}$ Chroinin M, Greenstone IR, Danish A, et al. Long-acting $\beta_{2^{-}}$ agonists versus placebo in addition to inhaled corticosteroids in children and adults with chronic asthma. Cochrane Database Syst Rev 2005; 4: CD005535.

46 O'Byrne PM, Bisgaard H, Godard PP, et al. Budesonide/ formoterol combination therapy as both maintenance and reliever medication in asthma. Am J Respir Crit Care Med 2005; 171: 129-136.

47 Verberne AA, Hop WC, Creyghton FB, et al. Airway responsiveness after a single dose of salmeterol and during four months of treatment in children with asthma. J Allergy Clin Immunol 1996; 97: 938-946.

48 Simons FE, Gerstner TV, Cheang MS. Tolerance to the bronchoprotective effect of salmeterol in adolescents with exercise-induced asthma using concurrent inhaled glucocorticoid treatment. Pediatrics 1997; 99: 655-659.

49 Halfhide C, Evans HJ, Couriel J. Inhaled bronchodilators for cystic fibrosis. Cochrane Database Syst Rev 2005; 4: CD003428.

50 Tomerak AAT, Vyas H, Lakhanpaul $\mathrm{M}$, et al. Inhaled $\beta_{2}$-agonists for non-specific chronic cough in children. Cochrane Database Syst Rev 2005; 3: CD005373.

51 Flores G, Horwitz RI, Flores G, et al. Efficacy of $\beta_{2}$-agonists in bronchiolitis: a reappraisal and meta-analysis. Pediatrics 1997; 100: 233-239.

52 GlaxoSmithKline, A Randomized, Double-Blind, DoubleDummy, Placebo-Controlled, Parallel-Group Clinical Trial of 4 Weeks Treatment With SEREVENT Inhalation Aerosol, $25 \mu \mathrm{g}$ BID, $50 \mu \mathrm{g}$ BID, and Placebo Administered via a Valved Holding Chamber With Facemask in Subjects With Asthma Aged 24 to 47 
Months. www.gsk-clinicalstudyregister.com/files/pdf/2500.pdf Date last updated: July 7, 2005. Date last accessed: May 12, 2009.

53 Bisgaard H, Le Roux P, Bjåmer D, et al. Budesonide/formoterol maintenance plus reliever therapy. a new strategy in pediatric asthma. Chest 2006; 130: 1733-1743.

54 Bateman ED, Boushey HA, Bousquet J, et al. Can guideline-defined asthma control be achieved?: The Gaining Optimal Asthma Control Study. Am J Respir Crit Care Med 2004; 170: 836-844.

55 Jantikar A, Brashier B, Maganji M, et al. Comparison of bronchodilator responses of levosalbutamol and salbutamol given via a pressurized metered dose inhaler: a randomized, double blind, single-dose, crossover study. Respir Med 2007; 101: 845-849.

56 Panickar JR, Kenia P, Silverman M, et al. Intramuscular triamcinolone for difficult asthma. Pediatr Pulmonol 2005; 39: 421-425.

57 Smith M, Iqbal SMSI, Rowe $\mathrm{BH}$, et al. Corticosteroids for hospitalised children with acute asthma. Cochrane Database Syst Rev 2003; 1: CD002886.

58 Camargo CA, Spooner C, Rowe BH. Continuous versus intermittent $\beta$-agonists for acute asthma. Cochrane Database Syst Rev 2003; 4: CD001115.

59 Rodrigo GJ, Castro-Rodriguez JA. Anticholinergics in the treatment of children and adults with acute asthma: a systematic review with meta-analysis. Thorax 2005; 60: 740-746.

60 Bohn D, Kalloghlian A, Jenkins J, et al. Intravenous salbutamol in the treatment of status asthmaticus in children. Crit Care Med 1984; 12: 892-896.

61 Mitra A, Bassler D, Watts K, et al. Intravenous aminophylline for acute severe asthma in children over two years receiving inhaled bronchodilators. Cochrane Database Syst Rev 2005; 2: CD001276.

62 Rowe BH, Bretzlaff JA, Bourdon C, et al. Magnesium sulfate for treating exacerbations of acute asthma in the emergency department. Cochrane Database Syst Rev 2000; 1: CD001490.

63 Barnard A. Management of an acute asthma attack. Aust Fam Physician 2005; 34: 531-534.

64 Allen JY, Macias CG. The efficacy of ketamine in pediatric emergency department patients who present with acute severe asthma. Ann Emerg Med 2005; 46: 43-50.

65 Levine DA. Novel therapies for children with severe asthma. Curr Opin Pediatr 2008; 20: 261-265.

66 ISRCTN Register, A randomised, placebo controlled study of nebulised magnesium in acute severe asthma in children. www.controlled-trials.com/ISRCTN81456894 Date last updated: May 11, 2009. Date last accessed: May 12, 2009.

67 Farrell PM, Kosorok MR, Laxova A, et al. Nutritional benefits of neonatal screening for cystic fibrosis. Wisconsin Cystic Fibrosis Neonatal Screening Study Group. N Engl J Med 1997; 337: 963-969.

68 Armstrong DS, Grimwood K, Carzino R, et al. Lower respiratory infection and inflammation in infants with newly diagnosed cystic fibrosis. BMJ 1995; 310: 1571-1572.

69 Smyth A, Walters S. Prophylactic antibiotics for cystic fibrosis. Cochrane Database Syst Rev 2003; 3: CD001912.

70 Stutman HR, Lieberman JM, Nussbaum E, et al. Antibiotic prophylaxis in infants and young children with cystic fibrosis: a randomised controlled trial. J Pediatr 2002; 140: 229-305.

71 Ratjen F, Comes G, Paul K, et al. Effect of continuous antistaphylococcal therapy on the rate of $P$. aeruginosa acquisition in patients with cystic fibrosis. Pediatr Pulmonol 2001; 31: 13-16.

72 Nasr SZ, Kuhns LR, Brown RW, et al. Use of computerized tomography and chest $\mathrm{x}$-rays in evaluating efficacy of aerosolized recombinant human DNase in cystic fibrosis patients younger than 5 years: a preliminary study. Pediatr Pulmonol 2001; 31: $377-382$

73 Subbarao P, Balkovec S, Solomon M, et al. Pilot study of safety and tolerability of inhaled hypertonic saline in infants with cystic fibrosis. Pediatr Pulmonol 2007; 42: 471-476.
74 Nationwide Children's Hospital, Efficacy of Pulmozyme in Infants and Young Children With Cystic Fibrosis. http:// clinicaltrials.gov/ct2/show/

NCT00179998?term5dornase+alfa\&rank53 Date last updated: November 9, 2005. Date last accessed: May 12, 2009.

75 Brody AS, Klein JS, Molina PL, et al. High-resolution computed tomography in young patients with cystic fibrosis: distribution of abnormalities and correlation with pulmonary function tests. J Pediatr 2004; 145: 32-38.

76 Lum S, Gustafsson P, Ljungberg H, et al. Early detection of cystic fibrosis lung disease: multiple-breath washout versus raised volume tests. Thorax 2007; 62: 341-347.

77 Aurora P, Bush A, Gustafsson P, et al. Multiple-breath washout as a marker of lung disease in preschool children with cystic fibrosis. Am J Respir Crit Care Med 2005; 171: 249-256.

78 CF Therapeutics Development Network Coordinating Center, Cystic Fibrosis Foundation, National Heart, Lung, and Blood Institute, Infant Study of Inhaled Saline in Cystic Fibrosis (ISIS) http://clinicaltrials.gov/ct2/show/NCT00709280?term5\%22cystic+ fibrosis\%22\&rank586 Date last updated: August 3, 2009. Date last accessed: May 12, 2009.

79 Dodge JA, Turck D. Cystic fibrosis: nutritional consequences and management. Best Pract Res Clin Gastroenterol 2006; 20: 531-546.

80 Mahadeva R, Webb K, Westerbeek RC, et al. Clinical outcome in relation to care in centres specialising in cystic fibrosis: cross sectional study. BMJ 1998; 316: 1771-1775.

81 Smyth RL, van Velzen D, Smyth AR, et al. Strictures of ascending colon in cystic fibrosis and high-strength pancreatic enzymes. Lancet 1994; 343: 85-86.

82 Vyas H, Matthew DJ, Milla PJ. A comparison of enteric coated microspheres with enteric coated tablet pancreatic enzyme preparations in cystic fibrosis. A controlled study. Eur J Pediatr 1990; 149: 241-243.

83 Brady MS, Garson JL, Krug SK, et al. An enteric-coated highbuffered pancrelipase reduces steatorrhea in patients with cystic fibrosis: a prospective, randomized study. J Am Diet Assoc 2006; 106: 1181-1186.

$84 \mathrm{Ng} \mathrm{SM}$, Jones AP. Drug therapies for reducing gastric acidity in people with cystic fibrosis. Cochrane Database Syst Rev 2003; 2: CD003424.

85 Borowitz D, Goss CH, Limauro S, et al. Study of a novel pancreatic enzyme replacement therapy in pancreatic insufficient subjects with cystic fibrosis. J Pediatr 2006; 149: 658-662.

86 Blackman SM, Deering-Brose R, McWilliams R, et al. Relative contribution of genetic and nongenetic modifiers to intestinal obstruction in cystic fibrosis. Gastroenterology 2006; 131: 1030-1039.

87 O'Halloran SM, Gilbert J, McKendrick OM, et al. Gastrografin in acute meconium ileus equivalent. Arch Dis Child 1986; 61: $1128-1130$.

88 Poustie VJ, Russell JE, Watling RM, et al. Oral protein energy supplements for children with cystic fibrosis: CALICO multicentre randomised controlled trial. BMJ 2006; 332: 632-636.

89 Smyth RL, Walters S. Oral calorie supplements for cystic fibrosis. Cochrane Database Syst Rev 2005; 1: CD000406.

90 O'Neil C, Shevill E, Chang AB. Vitamin A supplementation for cystic fibrosis. Cochrane Database Syst Rev 2008; 1: CD006751.

91 Conway SP, Wolfe SP, Brownlee KG, et al. Vitamin K status among children with cystic fibrosis and its relationship to bone mineral density and bone turnover. Pediatr 2005; 115: 1325-1331.

92 Urquhart DS, Fitzpatrick M, Cope J, et al. Vitamin K prescribing patterns and bone health surveillance in UK children with cystic fibrosis. J Hum Nutr Diet 2007; 20: 605-610.

93 Emerson J, Rosenfeld M, McNamara S, et al. Pseudomonas aeruginosa and other predictors of mortality and morbidity in young children with cystic fibrosis. Pediatr Pulmonol 2002; 34: 91-100. 
94 Wood DM, Smyth AR. Antibiotic strategies for eradicating Pseudomonas aeruginosa in people with cystic fibrosis. Cochrane Database Syst Rev 2006; 1: CD004197.

95 Flume PA, O'Sullivan BP, Robinson KA, et al. Cystic fibrosis pulmonary guidelines: chronic medications for maintenance of lung health. Am J Respir Crit Care Med 2007; 176: 957-969.

96 Ramsey BW, Pepe MS, Quan JM, et al. Intermittent administration of inhaled tobramycin in patients with cystic fibrosis. Cystic Fibrosis Inhaled Tobramycin Study Group. N Engl J Med 1999; 340: 23-30.

97 Ryan G, Mukhopadhyay S, Singh M. Nebulised anti-pseudomonal antibiotics for cystic fibrosis. Cochrane Database Syst Rev 2003; 3: CD001021.

98 Saiman L, Marshall BC, Mayer-Hamblett N, et al. Azithromycin in patients with cystic fibrosis chronically infected with Pseudomonas aeruginosa: a randomized controlled trial. JAMA 2003; 290: 1749-1756.

99 Clement A, Tamalet A, Leroux E, et al. Long term effects of azithromycin in patients with cystic fibrosis: a double blind, placebo controlled trial. Thorax 2006; 61: 895-902.

100 Liou TG, Adler FR, Fitzsimmons SC, et al. Predictive 5-year survivorship model of cystic fibrosis. Am J Epidemiol 2001; 153 345-352.

101 Fowler CE, Soothill JS, Oakes L. MICs of rifampicin and chloramphenicol for mucoid Pseudomonas aeruginosa strains are lower when human lactoferrin is present. J Antimicrob Chemother 1997; 40: 877-879.

102 Gold R, Carpenter S, Heurter H, et al. Randomized trial of ceftazidime versus placebo in the management of acute respiratory exacerbations in patients with cystic fibrosis. J Pediatr 1987; 111: 907-913.

103 Regelmann WE, Elliott GR, Warwick WJ, et al. Reduction of sputum Pseudomonas aeruginosa density by antibiotics improves lung function in cystic fibrosis more than do bronchodilators and chest physiotherapy alone. Am Rev Respir Dis 1990; 141: 914-921.

104 Johnson C, Butler SM, Konstan MW, et al. Factors influencing outcomes in cystic fibrosis: a center-based analysis. Chest 2003; 123: 20-27.

105 Elphick H, Tan A. Single versus combination intravenous antibiotic therapy for people with cystic fibrosis. Cochrane Database Syst Rev 2005; 1: CD002007.

106 Blumer JL, Saiman L, Konstan MW, et al. The efficacy and safety of meropenem and tobramycin versus ceftazidime and tobramycin in the treatment of acute pulmonary exacerbations in patients with cystic fibrosis. Chest 2005; 128: 2336-2346.

107 Remmington T, Jahnke N, Harkensee C. Oral anti-pseudomonal antibiotics for cystic fibrosis. Cochrane Database Syst Rev 2007; 3 : CD005405.

108 Rosenberg SM, Schramm CM, Rosenberg SM, et al. Predictive value of pulmonary function testing during pulmonary exacerbations in cystic fibrosis. Pediatr Pulmonol 1993; 16: 227-235.

109 Smyth A, Tan $\mathrm{KH}-\mathrm{V}$, Bunn H. Once daily versus multiple daily dosing with intravenous aminoglycosides for cystic fibrosis. Cochrane Database Syst Rev 2000; 4: CD002009.

110 Smyth A, Tan KH, Hyman-Taylor P, et al. Once versus threetimes daily regimens of tobramycin treatment for pulmonary exacerbations of cystic fibrosis - the TOPIC study: a randomised controlled trial. Lancet 2005; 365: 573-578.

111 Smith AL, Fiel SB, Mayer H, et al. Susceptibility testing of Pseudomonas aeruginosa isolates and clinical response to parenteral antibiotic administration: lack of association in cystic fibrosis. Chest 2003; 123: 1495-1502.

112 Aaron SD, Vandemheen KL, Ferris W, et al. Combination antibiotic susceptibility testing to treat exacerbations of cystic fibrosis associated with multi-resistant bacteria. Lancet 2005; 366: 463-471.
113 Breen L, Aswani N. Elective versus symptomatic intravenous antibiotic therapy for cystic fibrosis. Cochrane Database Syst Rev 2001; 4: CD002767.

114 Bosworth DG, Nielson DW. Effectiveness of home versus hospital care in the routine treatment of cystic fibrosis. Pediatr Pulmonol 1997; 24: 42-47.

115 Wolter JM, Bowler SD, Nolan PJ, et al. Home intravenous therapy in cystic fibrosis: a prospective randomized trial examining clinical, quality of life and cost aspects. Eur Respir J 1997; 10: 896-900.

116 UK Cystic Fibrosis Trust Antibiotic Group. Antibiotic Treatment for Cystic Fibrosis. 3rd Edn. London, UK Cystic Fibrosis Trust, 2009.

117 Ratjen F, Munck A, Kho P. Short and long term efficacy of inhaled tobramycin in early $P$. aeruginosa: the ELITE study. Pediatr Pulmonol 2008; 43: 319.

118 Geller DE, Konstan MW, Smith J, et al. Novel tobramycin inhalation powder in cystic fibrosis subjects: pharmacokinetics and safety. Pediatr Pulmonol 2007; 42: 307-313.

119 Stevens DA, Moss RB, Kurup VP, et al. Allergic bronchopulmonary aspergillosis in cystic fibrosis - state of the art: Cystic Fibrosis Foundation Consensus Conference. Clin Infect Dis 2003; 37: S225-S264.

120 Mastella G, Rainisio M, Harms HK, et al. Allergic bronchopulmonary aspergillosis in cystic fibrosis. A European epidemiological study. Epidemiologic Registry of Cystic Fibrosis. Eur Respir J 2000; 16: 464-471.

121 Wark PAB, Gibson PG, Wilson AJ. Azoles for allergic bronchopulmonary aspergillosis associated with asthma. Cochrane Database Syst Rev 2004; 3: CD001108.

122 Hennig S, Wainwright CE, Bell SC, et al. Population pharmacokinetics of itraconazole and its active metabolite hydroxyitraconazole in paediatric cystic fibrosis and bone marrow transplant patients. Clin Pharmacokinet 2006; 45: 1099-1114.

123 Thomson JM, Wesley A, Byrnes CA, et al. Pulse intravenous methylprednisolone for resistant allergic bronchopulmonary aspergillosis in cystic fibrosis. Pediatr Pulmonol 2006; 41: 164-170.

124 van der Ent CK, Hoekstra H, Rijkers GT. Successful treatment of allergic bronchopulmonary aspergillosis with recombinant antiIgE antibody. Thorax 2007; 62: 276-277.

125 Hilliard T, Edwards S, Buchdahl R, et al. Voriconazole therapy in children with cystic fibrosis. J Cyst Fibros 2005; 4: 215-220.

126 Skov M, Main KM, Sillesen IB, et al. Iatrogenic adrenal insufficiency as a side-effect of combined treatment of itraconazole and budesonide. Eur Respir J 2002; 20: 127-133.

127 Kanthan SK, Bush A, Kemp M, et al. Factors effecting impact of Aspergillus fumigatus sensitization in cystic fibrosis. Pediatr Pulmonol 2007; 42: 785-793.

128 Henke M, Ratjen F. Mucolytics in cystic fibrosis. Paediatr Respir Rev 2007; 8: 24-29.

129 Fuchs HJ, Borowitz DS, Christiansen DH, et al. Effect of aerosolised recombinant human DNase on exacerbations of respiratory symptoms and on pulmonary function in patients with cystic fibrosis. N Engl J Med 1994; 331: 637-642.

130 Quan JM, Tiddens HA, Sy JP, et al. A two-year randomized, placebo-controlled trial of dornase alfa in young patients with cystic fibrosis with mild lung function abnormalities. J Pediatr 2001; 139: 813-820.

131 Ratjen F. Restoring airway surface liquid in cystic fibrosis. N Engl J Med 2006; 354: 291-293.

132 Wark PAB, McDonald V, Jones AP. Nebulised hypertonic saline for cystic fibrosis. Cochrane Database Syst Rev 2005; 3: CD001506.

133 Elkins MR, Robinson M, Rose BR, et al. A controlled trial of longterm inhaled hypertonic saline in patients with cystic fibrosis. N Engl J Med 2006; 354: 229-240.

134 Suri R, Metcalfe C, Lees B, et al. Comparison of hypertonic saline and alternate-day or daily recombinant human deoxyribonuclease in children with cystic fibrosis: a randomised trial. Lancet 2001; 358: 1316-1321. 
135 UK CF Trust. UK Cystic Fibrosis Trust Annual Data Report 2004. Dundee, University of Dundee, 2006.

136 Camara M, Williams P, Hardman A. Controlling infection by tuning in and turning down the volume of bacterial small-talk. Lancet Infect Dis 2002; 2: 667-676.

137 Moss RB, Babin S, Hsu YP, et al. Allergy to semisynthetic penicillins in cystic fibrosis. J Pediatr 1984; 104: 460-466.

138 Al Aloul M, Miller H, Alapati S, et al. Renal impairment in cystic fibrosis patients due to repeated intravenous aminoglycoside use. Pediatr Pulmonol 2005; 39: 15-20.

139 Bjarnsholt T, Jensen PO, Rasmussen TB, et al. Garlic blocks quorum sensing and promotes rapid clearing of pulmonary P. aeruginosa infections. Microbiol 2005; 151: 3873-3880.

140 DeWitt RC, Wu Y, Renegar KB, et al. Glutamine-enriched total parenteral nutrition preserves respiratory immunity and improves survival to a Pseudomonas pneumonia. J Surg Res 1999; 84: 13-18.

141 Boelens P, Nijveldt R, Houdijk A, et al. Glutamine alimentation in catabolic state. J Nutrition 2001; 131: 2569S-2577S.

142 Grasemann H, Kurtz F, Ratjen F. Inhaled L-arginine improves exhaled nitric oxide and pulmonary function in patients with cystic fibrosis. Am J Respir Crit Care Med 2006; 174: 208-212.

143 Soothill J, Hawkins C, Anggard E, et al. Therapeutic use of bacteriophages. Lancet Infect Dis 2004; 4: 544-545.

144 ISRCTN Register. A randomised controlled trial (pilot study) of the use of macerated garlic in patients with cystic fibrosis who have pulmonary infection with Pseudomonas aeruginosa. www. controlled-trials.com/ISRCTN21133397/garlic Date last updated: January 7, 2009. Date last accessed: May 12, 2009.

145 ISRCTN Register. Glutamine supplementation for cystic fibrosis. www.controlled-trials.com/ISRCTN22534872/glutamine Date last updated: August 1, 2008. Date last accessed: May 12, 2009.

146 Cheng K, Ashby D, Smyth R. Oral steroids for cystic fibrosis. Cochrane Database Syst Rev 1999; 4: CD000407.

147 Balfour-Lynn IM, Lees B, Hall P, et al. Multicenter randomized controlled trial of withdrawal of inhaled corticosteroids in cystic fibrosis. Am J Respir Crit Care Med 2006; 173: 1356-1362.

148 Lands LC, Stanojevic S. Oral non-steroidal anti-inflammatory drug therapy for cystic fibrosis. Cochrane Database Syst Rev 2007; 4: CD001505.

149 Koh YY, Park Y, Jeong JH, et al. The effect of regular salbutamol on lung function and bronchial responsiveness in patients with primary ciliary dyskinesia. Chest 2000; 117: 427-433.

150 Loukides S, Kharitonov S, Wodehouse T, et al. Effect of arginine on mucociliary function in primary ciliary dyskinesia. Lancet 1998; 352: 371-372.

151 Noone PG, Bennett WD, Regnis JA, et al. Effect of aerosolized uridine-5'-triphosphate on airway clearance with cough in patients with primary ciliary dyskinesia. Am J Respir Crit Care Med 1999; 160: 144-149.

152 Stafanger G, Garne S, Howitz P, et al. The clinical effect and the effect on the ciliary motility of oral $\mathrm{N}$-acetylcysteine in patients with cystic fibrosis and primary ciliary dyskinesia. Eur Respir J 1988; 1: 161-167.

153 Phillips GE, Thomas S, Heather S, et al. Airway response of children with primary ciliary dyskinesia to exercise and $\beta_{2}$ agonist challenge. Eur Respir J 1998; 11: 1389-1391.

154 Desai M, Weller PH, Spencer DA. Clinical benefit from nebulized human recombinant DNase in Kartagener's syndrome. Pediatr Pulmonol 1995; 20: 307-308.

155 ten Berge M, Brinkhorst G, Kroon AA, et al. DNase treatment in primary ciliary dyskinesia - assessment by nocturnal pulse oximetry. Pediatr Pulmonol 1999; 27: 59-61.

156 El Abiad NM, Clifton S, Nasr SZ. Long-term use of nebulized human recombinant DNase1 in two siblings with primary ciliary dyskinesia. Respir Med 2007; 101: 2224-2226.
157 Bush A, Chodhari R, Collins N, et al. Primary ciliary dyskinesia: current state of the art. Arch Dis Child 2007; 92: 1136-1140.

158 Wills PJ, Wodehouse T, Corkery K, et al. Short-term recombinant human DNase in bronchiectasis. Effect on clinical state and in vitro sputum transportability. Am J Respir Crit Care Med 1996; 154 413-417.

159 Ellerman A, Bisgaard H. Longitudinal study of lung function in a cohort of primary ciliary dyskinesia. Eur Respir J 1997; 10 2376-2379.

160 Wolter J, Seeney S, Bell S, et al. Effect of long term treatment with azithromycin on disease parameters in cystic fibrosis: a randomised trial. Thorax 2002; 57: 212-216.

161 Equi A, Balfour-Lynn IM, Bush A, et al. Long term azithromycin in children with cystic fibrosis. Lancet 2002; 360: 978-984.

162 Murphy TF, Henderson FW, Clyde WA Jr, et al. Pneumonia: an eleven-year study in a pediatric practice. Am J Epidemiol 1981; 113: $12-21$.

163 Heiskanen-Kosma T, Korppi M, Jokinen C, et al. Etiology of childhood pneumonia: serologic results of a prospective, population-based study. Pediatr Infect Dis J 1998; 17: 986-991.

164 Poehling KA, Talbot TR, Griffin MR, et al. Invasive pneumococcal disease among infants before and after introduction of pneumococcal conjugate vaccine. JAMA 2006; 295: 1668-1674.

165 Felmingham D, Reinert RR, Hirakata $Y$, et al. Increasing prevalence of antimicrobial resistance among isolates of Streptococcus pneumoniae from the PROTEKT surveillance study, and compatative in vitro activity of the ketolide, telithromycin. J Antimicrob Chemother 2002; 50: Suppl. S1, 25-37.

166 Felmingham D, Farrell DJ, Reinert RR, et al. Antibacterial resistance among children with community-acquired respiratory tract infections (PROTEKT 1999-2000). J Infect 2004; 48: 39-55.

167 Schito GC. Is antimicrobial resistance also subject to globalization? Clin Microbiol Infect 2002; 8: Suppl. 3, 1-8.

168 Sogstad MK, Littauer P, Aaberge IS, et al. Rapid spread in Norway of an erythromycin-resistant pneumococcal clone, despite low usage of macrolides. Microb Drug Resist 2007; 13: 29-36.

169 Esposito S, Bosis S, Cavagna R, et al. Characteristics of Streptococcus pneumoniae and atypical bacterial infections in children 2-5 years of age with community-acquired pneumonia. Clin Infect Dis 2002; 35: 1345-1352.

170 Virkki R, Juven T, Rikalainen H, et al. Differentiation of bacterial and viral pneumonia in children. Thorax 2002; 57: 438-441.

171 Kabra SK, Lodha R, Pandey RM. Antibiotics for community acquired pneumonia in children. Cochrane Database Syst Rev 2006; 3: CD004874.

172 Rojas MX, Granados C. Oral antibiotics versus parenteral antibiotics for severe pneumonia in children. Cochrane Database Syst Rev 2006; 2: CD004979.

173 Duke $\mathrm{T}$, Poka H, Dale $\mathrm{F}$, et al. Chloramphenicol versus benzylpenicillin and gentamicin for the treatment of severe pneumonia in children in Papua New Guinea: a randomised trial. Lancet 2002; 359: 474-480.

174 Vuori-Holopainen E, Peltola H, Kallio MJ, et al. Narrow- versus broad-spectrum parenteral anatimicrobials against common infections of childhood: a prospective and randomised comparison between penicillin and cefuroxime. Eur J Pediatr 2000; 159: 878-884.

175 Atkinson M, Lakhanpaul M, Smyth A, et al. Comparison of oral amoxicillin and intravenous benzyl penicillin for community acquired pneumonia in children (PIVOT trial): a multicentre pragmatic randomised controlled equivalence trial. Thorax 2007 62: 1102-1106.

176 Eastham KM, Freeman R, Kearns AM, et al. Clinical features, aetiology and outcome of empyema in children in the north east of England. Thorax 2004; 59: 522-525. 
177 Buckingham SC, King MD, Miller ML. Incidence and etiologies of complicated parapneumonic effusions in children, 1996 to 2001. Pediatr Infect Dis J 2003; 22: 499-504.

178 Byington $\mathrm{CL}$, Korgenski $\mathrm{K}$, Daly $\mathrm{J}$, et al. Impact of the pneumococcal conjugate vaccine on pneumococcal parapneumonic empyema. Pediatr Infect Dis J 2006; 25: 250-254.

179 Ferguson AD, Prescott RJ, Selkon JB, et al. The clinical course and management of thoracic empyema. QJM 1996; 89: 285-289.

180 Balfour-Lynn IM, Abrahamson E, Cohen G, et al. BTS guidelines for the management of pleural infection in children. Thorax 2005; 60: Suppl. 1, i1-i21.

181 Avansino JR, Goldman B, Sawin RS, et al. Primary operative versus nonoperative therapy for pediatric empyema: a metaanalysis. Pediatrics 2005; 115: 1652-1659.

182 Thomson AH, Hull J, Kumar MR, et al. Randomised trial of intrapleural urokinase in the treatment of childhood empyema. Thorax 2002; 57: 343-347.

183 Singh M, Mathew JL, Chandra S, et al. Randomized controlled trial of intrapleural streptokinase in empyema thoracis in children. Acta Paediatr 2004; 93: 1443-1445.

184 Sonnappa S, Cohen G, Owens CM, et al. Comparison of urokinase and video-assisted thoracoscopic surgery for treatment of childhood empyema. Am J Respir Crit Care Med 2006; 174: 221-227.

185 Carey JA, Hamilton JR, Spencer DA, et al. Empyema thoracis: a role for open thoracotomy and decortication. Arch Dis Child 1998; 79: 510-513.

186 Weinstein M, Restrepo R, Chait PG, et al. Effectiveness and safety of tissue plasminogen activator in the management of complicated parapneumonic effusions. Pediatr 2004; 113: e182-e185.

187 Wells RG, Havens PL. Intrapleural fibrinolysis for parapneumonic effusion and empyema in children. Radiology 2003; 228: 370-378.

188 ISRCTN Register. The second multi-centre intra-pleural sepsis trial (MIST2), to assess whether DNase or Alteplase, improve pleural fluid drainage in pleural infection. www.controlledtrials.com/ISRCTN57454527 Date last updated: September 10, 2007. Date last accessed: May 12, 2009.

189 Boogaard R, Huijsmans SH, Pijnenburg MW, et al Tracheomalacia and bronchomalacia in children: incidence and patient characteristics. Chest 2005; 128: 3391-3397.

190 Austin J, Ali T. Tracheomalacia and bronchomalacia in children: pathophysiology, assessment, treatment and anaesthesia management. Paediatr Anaesth 2003; 13: 3-11.

191 Carden KA, Boiselle PM, Waltz DA, et al. Tracheomalacia and tracheobronchomalacia in children and adults: an in-depth review. Chest 2005; 127: 984-1005.
192 Boogaard R, de Jongste JC, Merkus PJ. Pharmacotherapy of impaired mucociliary clearance in non-CF pediatric lung disease. A review of the literature. Pediatr Pulmonol 2007; 42: 989-1001.

193 Manzur AY, Kuntzer T, Pike M, et al. Glucocorticoid corticosteroids for Duchenne muscular dystrophy. Cochrane Database Syst Rev 2008; 1: CD003725.

194 Kissel JT, McDermott MP, Mendell JR, et al. Randomized, double-blind, placebo-controlled trial of albuterol in facioscapulohumeral dystrophy. Neurology 2001; 57: 1434-1440.

195 Fowler EG, Graves MC, Wetzel GT, et al. Pilot trial of albuterol in Duchenne and Becker muscular dystrophy. Neurology 2004; 62 1006-1008.

196 Kinali M, Mercuri E, Main M, et al. Pilot trial of albuterol in spinal muscular atrophy. Neurology 2002; 59: 609-610.

197 Weihl CC, Connolly AM, Pestronk A. Valproate may improve strength and function in patients with type III/IV spinal muscle atrophy. Neurology 2006; 67: 500-501.

198 Brouillette RT, Manoukian JJ, Ducharme FM, et al. Efficacy of fluticasone nasal spray for pediatric obstructive sleep apnea. J Pediatr 2001; 138: 838-844.

199 Goldbart AD, Goldman JL, Veling MC, et al. Leukotriene modifier therapy for mild sleep-disordered breathing in children. Am J Respir Crit Care Med 2005; 172: 364-370.

200 Kheirandish L, Goldbart AD, Gozal D. Intranasal steroids and oral leukotriene modifier therapy in residual sleep-disordered breathing after tonsillectomy and adenoidectomy in children. Pediatrics 2006; 117: e61-e66.

201 Wraith JE, Clarke LA, Beck M, et al. Enzyme replacement therapy for mucopolysaccharidosis I: a randomized, doubleblinded, placebo-controlled, multinational study of recombinant human alpha-L-iduronidase (laronidase). J Pediatr 2004; 144: 581-588.

202 Ozkan H, Atlihan F, Genel F, et al. IgA and/or IgG subclass deficiency in children with recurrent respiratory infections and its relationship with chronic pulmonary damage. J Investig Allergol Clin Immunol 2005; 15: 69-74.

203 Olinder-Nielsen AM, Granert C, Forsberg P, et al. Immunoglobulin prophylaxis in 350 adults with IgG subclass deficiency and recurrent respiratory tract infections: a long-term follow-up. Scand J Infect Dis 2007; 39: 44-50.

204 Cornely OA, Maertens J, Winston DJ, et al. Posaconazole versus fluconazole or itraconazole prophylaxis in patients with neutropenia. N Engl J Med 2007; 356: 348-359.

205 Rijnders BJ, Cornelissen JJ, Slobbe L, et al. Aerosolized liposomal amphotericin B for the prevention of invasive pulmonary aspergillosis during prolonged neutropenia: a randomized, placebo-controlled trial. Clin Infect Dis 2008; 46: 1401-1408. 